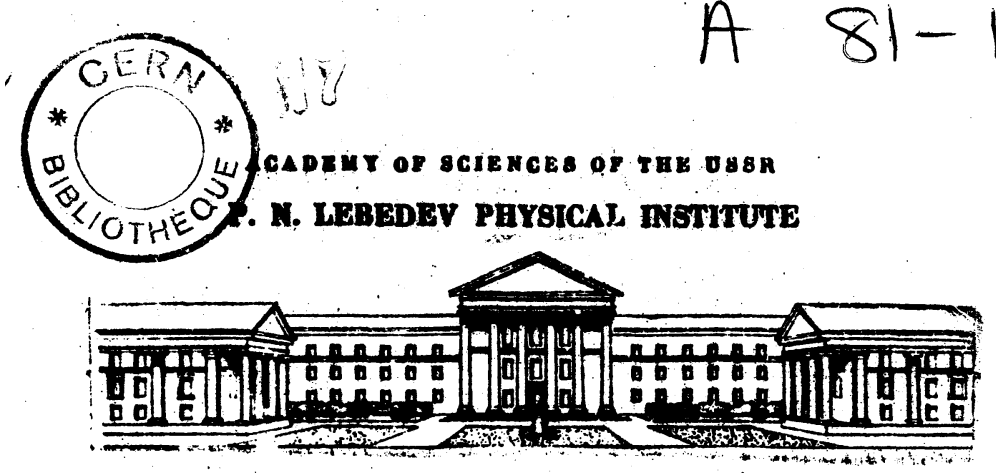

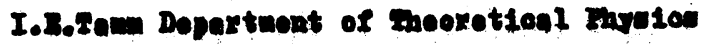

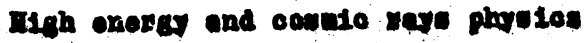

Ixoprint Io 109

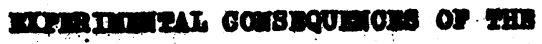

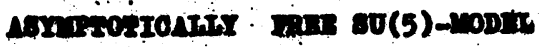

0.Xं. Tazochniter

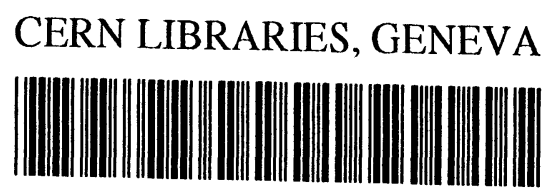

CM-P00067566

Vomecen. 1901 
The experimental conecquenoes of the anyptoticully $1 x 0$ 80(5)-theory axe presented which make it poseible to judge about ite rellebility. Whe phononenolog of the $\tau$-lepton in analyeed with opoolal attention pald to the nomolied oxotic proceases which way bocome a poxfoct teat for the prosent 80(5) theory. These propeges are ooppletely lowbidden within atandasd SU(5; Bchowes. The problen of the finite wass of the e, $\mu$-noutzino which io a loursomponont Dixac apinor intexacm

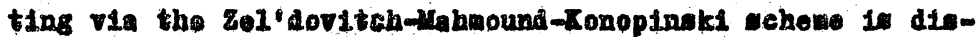
oumed. The finitoness of anoh noutrino paps to a peculiarity of the su(5) theory under disoussinn, although its value is not Isted hexe in unique way. The veraton of the theory wherein $m_{\nu} \leqslant 10^{-3} \mathrm{eV}$ is of expelal interest aince in this case the proton instability and the finite $e, \mu$-noutyino mass axe found to be explatned in a univeras way an manifostatione of tho exietence of superheary leptoquark boson in the theory. The poseibility Is pointed out to explain within the su(5) theory under considexatinn the exiotiditing experimental oituations concerning the search for parity violating effectg in atom. It if chown that the preaent SU(5) theory onoonater no difflculty in this respect and may recomodate itself to any experimental et of data, wherean the etandaxd achemes of 8U(5) unification way not. Also cosmological conequencen of the asymptot10ally exeo sU(5) theory are briefly discused and the latter in found to rether roamombiy explain a number of lacte about the vexy early evolution of the Univerae. 
ВВЕДВНИа,

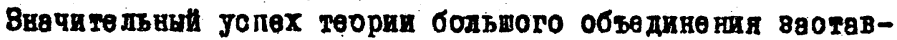
аяег в ностоящөө вреия сервевно думатз о всесторонне өкспе-

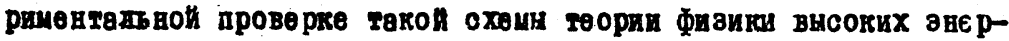

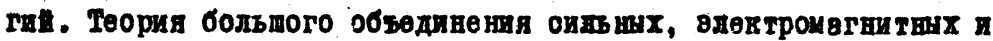
олебых оид уго оегодня представила педыи ряд пвтересных әкопе-

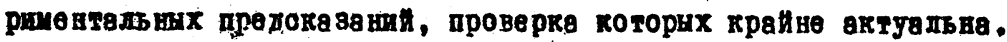

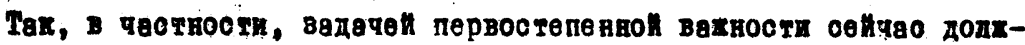
на отать әкепериментяльняя проверка Факта нестабивьности про-

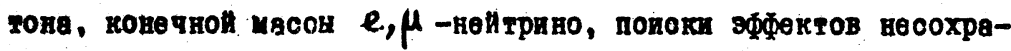
нөндя четвости в өтомах и других слөдствин. Вахно, что иногия

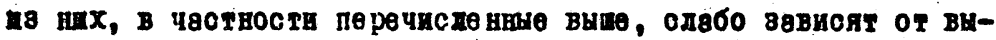
бора опредеденнои схемв реализаци теории бодьшого обзедине-

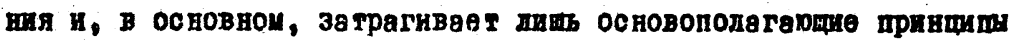

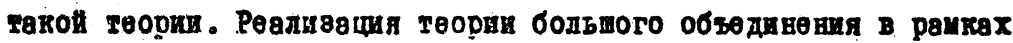
опредоденноң нодеди приводит к бодеө спешифически сдедо твия,

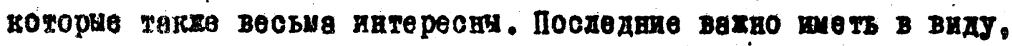

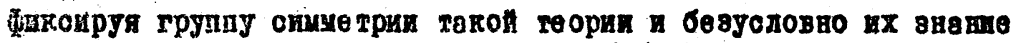

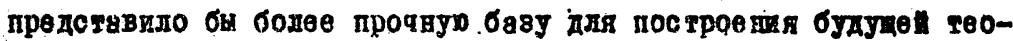
рау фияике внсоких эвергин.

Б последнеө вреия рядои өзторов $[I \div 4]$, предпочтене

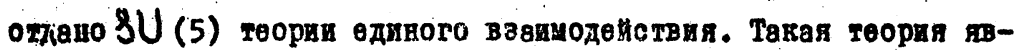

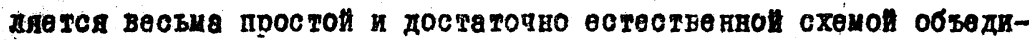

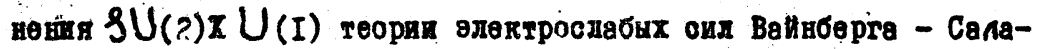

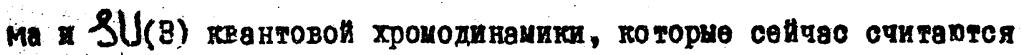
хоромо уозановлениыми Фрагментами будуден теории большого

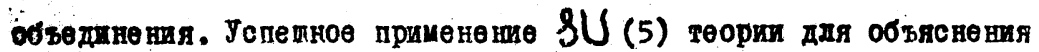
6ольшого круга экспериментальны фактов явдяется тому хорошии 


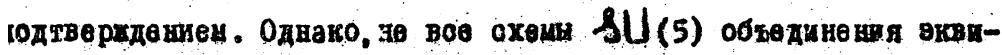

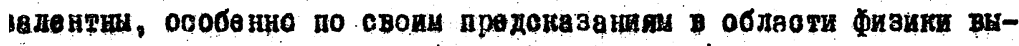

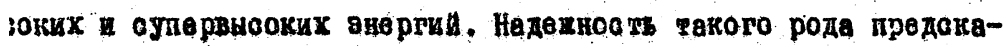

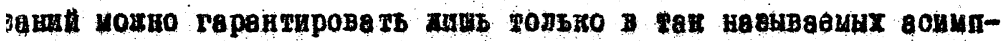

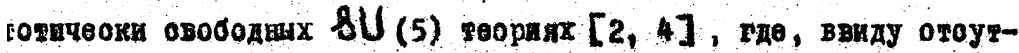

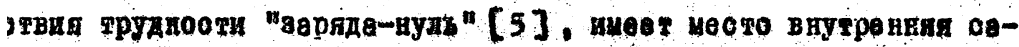

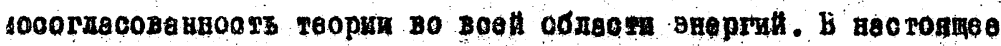

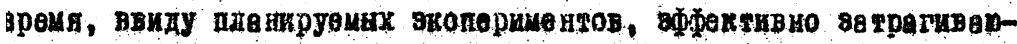

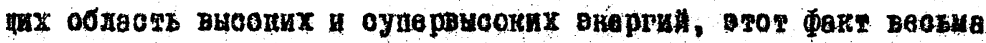

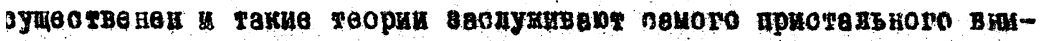

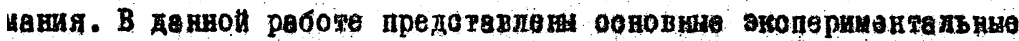

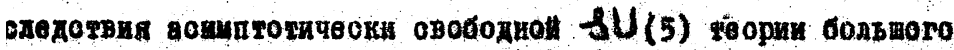

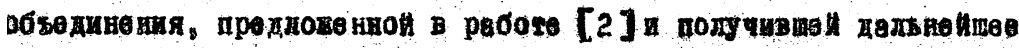

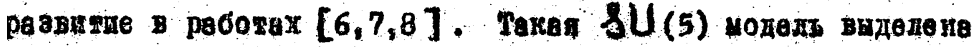

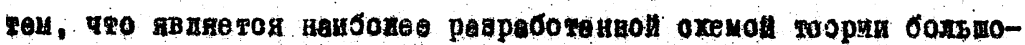

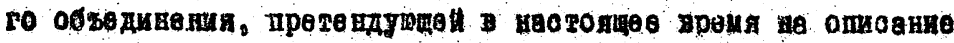
akcnopunears.

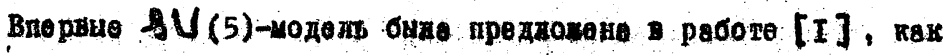

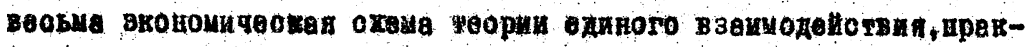

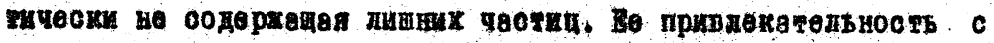

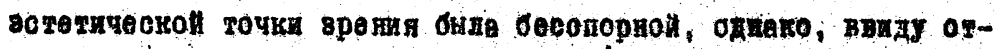

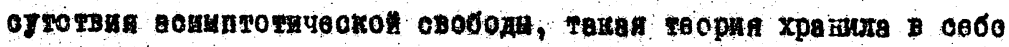

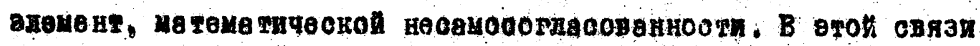

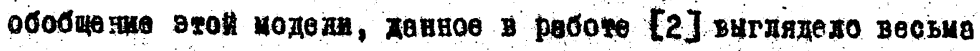

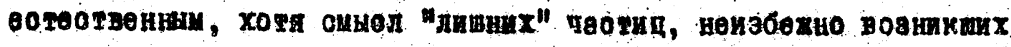

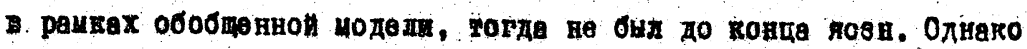
сегодня в овязи о ияменившено экоперииентальнси ситуациен

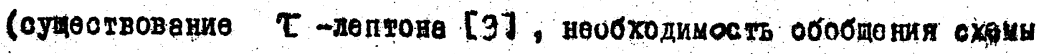




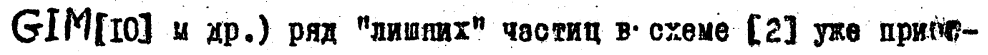
рөл свой ваконнй статус, а в неле, предсказани әтои төории

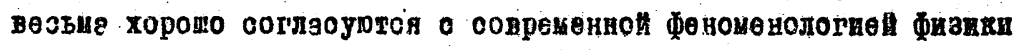
өлечен төрцхх честиц. Креткое опиеание модеди, необходиое для поникеняя дальнейего материяда, вдесь слөдует работе [7].

Латранжияв иодели состоит ив трех структуршх блоков

$$
\mathcal{L}=\mathcal{L}_{G}+\mathcal{L}_{Y}+\mathcal{L}_{\mathrm{s}}
$$

когорые построеня, сдедуя обытны правилам квантования сиотеи со связяия. Вдөсь блок $\mathcal{L}_{\epsilon}$ содержгт ввакиоденствие көлибровочного поля $V_{\mu}^{a}$ о $\phi, M, N$ - мультиплетяии окалярнах полен и оемьо $\left(B, \zeta, \eta, \vartheta_{L, R}, \psi_{L, R}\right)$-шуль тинле тани спи-

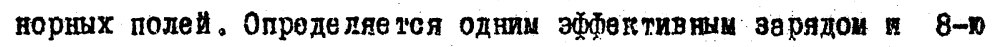
массовыми параметрами. Ваяимодействив типа Окавй Фикспруетоя блоком, которын являетоя нанболев сушественнон чаотьо дагрвн-

$$
\begin{aligned}
& \mathcal{L}_{Y}=-\left(i k_{F} f^{\alpha \beta \gamma}+k_{D} d^{\alpha \beta \gamma}\right) \bar{B}^{\alpha} \phi_{\beta} B^{\gamma} \\
& -\left[\left(\bar{B} \frac{\lambda}{2}\right)_{a}^{b}\left(h_{1} M_{b} \eta_{R}^{a}+h_{2} N_{b} \eta_{4}^{a}+h_{3} M^{+a} \zeta_{B}^{R}+h_{4} N^{b a} \zeta_{b}^{d}\right)+h . c .\right]
\end{aligned}
$$

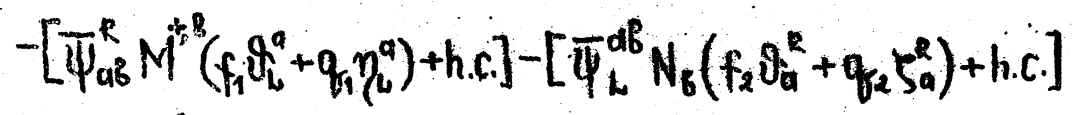

$$
\begin{aligned}
& -\left[\left(\bar{B} \frac{1}{2}\right)_{a}^{b}\left(\delta_{1} N_{b} \delta_{i}^{q}+\delta_{2} M^{+, a_{b}^{k}}\right)+h . c\right]
\end{aligned}
$$

хиана тесрия. Инонно бдагодаря падлегадему выбору посдеднего, цодель, обдадвл воинтотиєской овободои, онособня дөшовстри-

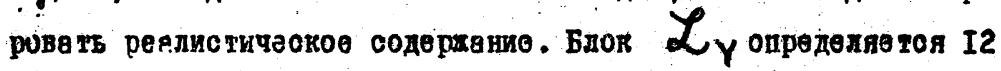

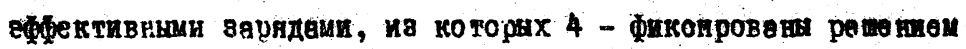
реноригоуппових уравнени, а 8 явлнотея подгоночнын пара-

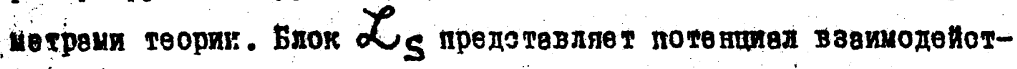
вия скалясных полен друг о другои и определяетоя,в ооновном, 


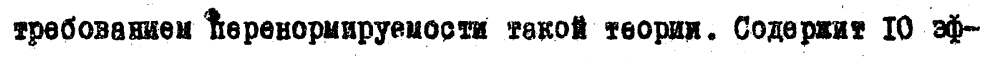

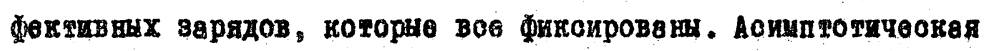
свобода модөди доназиветея, одөдуя реноригрупповы јравве-

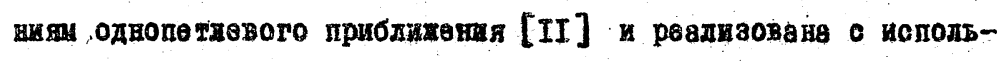
sованан I4 удътрафиоде тово веотабильвых фиксировевных точөк,

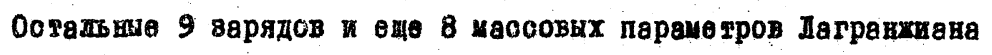
фикскрованы при подгонкө спектра масо төори и анвливе өө физических следствин.

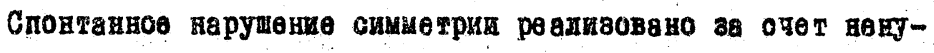
дөвых вакуумшых охиданші $\phi, M, N$ - скалярщх полен

$\omega=\left[\begin{array}{cccc}3 / 3 & & & \\ 3 / 3 & & \\ & s / 3 & \\ & & 3-5 & \\ & & & \end{array}\right]$

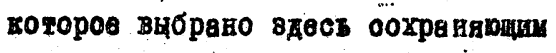

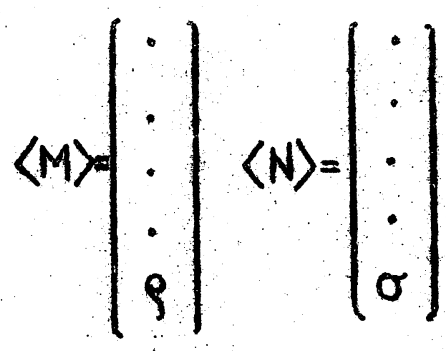

sU( 3$) \times U(1)$ crmue ppus

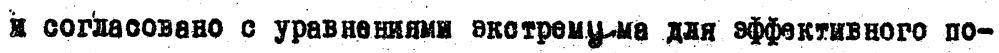
төнцияла төорик, наћлденного в древеснои приблихевии. Средн

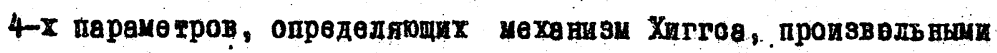

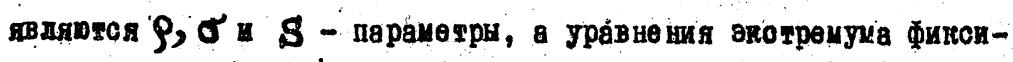
pура тодвко $t=2 / 5$ - отнотение

$t^{2}-\frac{11}{3} t+\frac{8}{3}=t\left[\frac{5}{t+2 / 3}-\frac{3}{2}\right] \frac{\rho^{2} \delta_{\phi^{2} M^{2}}^{2}+\sigma^{2} \delta_{\phi^{2} \mu^{2}}^{2}}{s^{2} \delta_{\phi^{4}}^{2}}$ Иерархия кадибровочвых ввяимодеНстви устанавливаетея выборои ДВух маоттабов иво0 ( определяптов $s \sim 10^{14} \mathrm{GeV} \rho \approx \sigma \sim 10^{2} \mathrm{GeV}$ и иамко 
покаэать, что факт такон иерархик оохраняетел прп јчете ра-

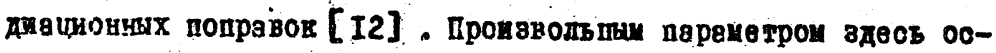
таетск $9 / \sigma$-огнопенио.

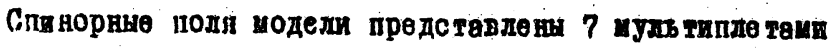
$\left(\psi_{L, R} ; \boldsymbol{U}_{L, R} ; B ; \zeta ; \eta\right.$ - иультнплетн), го горые содөрхат 49 оникорнх чвотиц: II дептонов и 88 пварнов. Воө

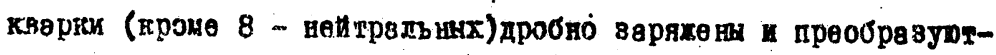
or кат тринлети относительно $\mathrm{SU}^{\mathrm{C}}(3)$ групш. феноменодотия дегккт. лептонов н кварнов, так тө как в псходно $S U(5)-$ модели [ [ ], представпенв двуия понолониями чвочиц

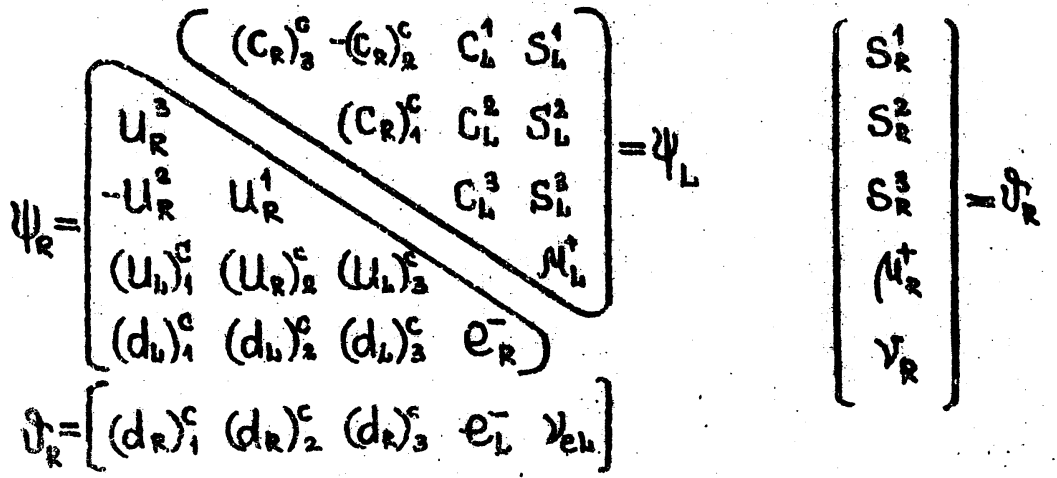

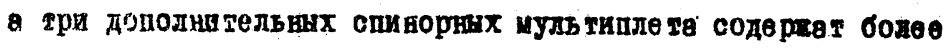

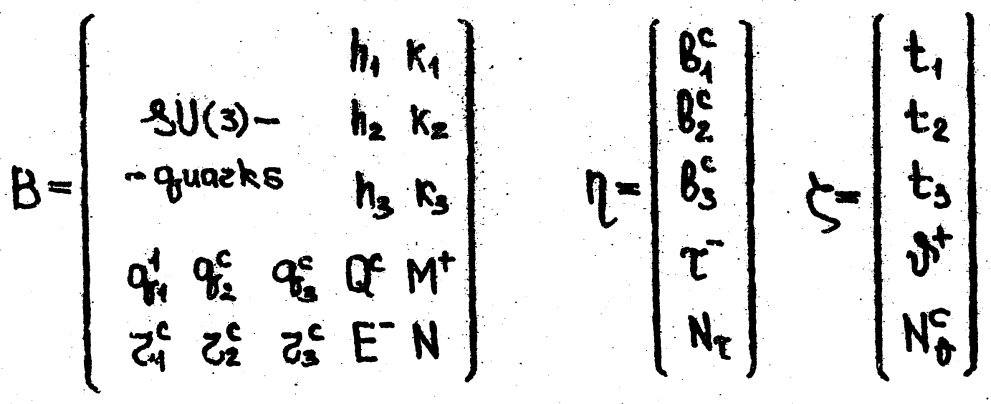




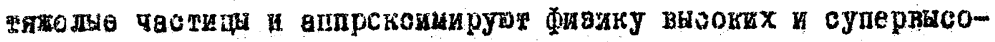

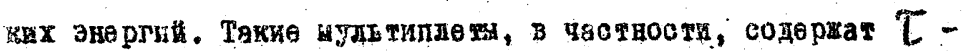

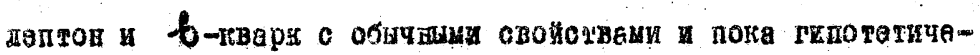

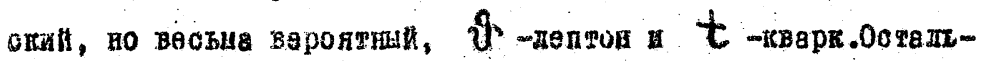

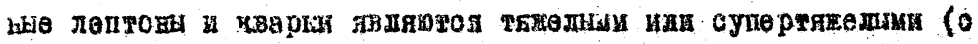

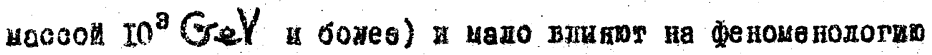

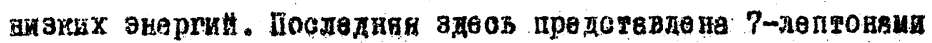

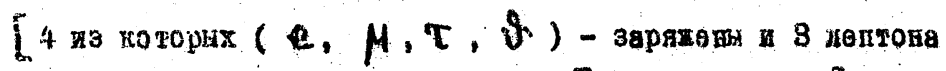

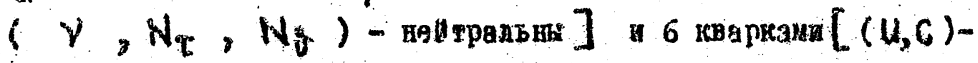

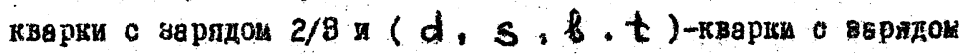

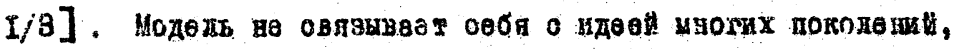

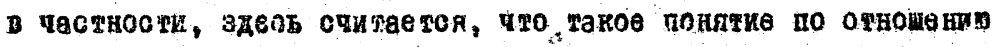

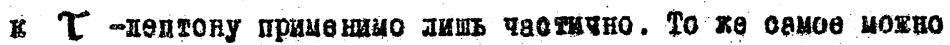
преднодвтуть танае в отномении нового $S$-лептона, которын

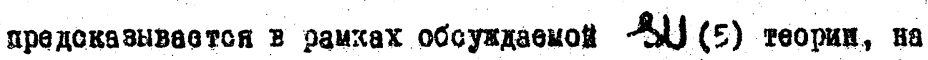

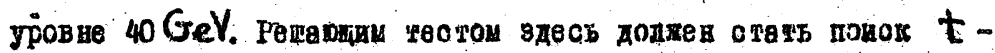

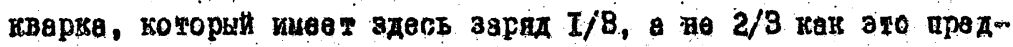

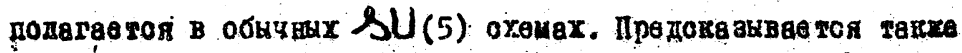

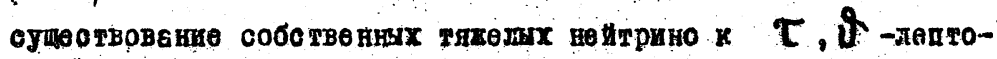
нам, хотя всо ооновные распады атих дептовов оопровохдатоя

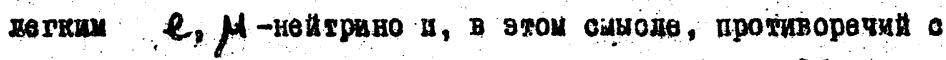

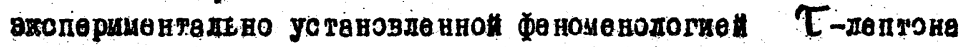

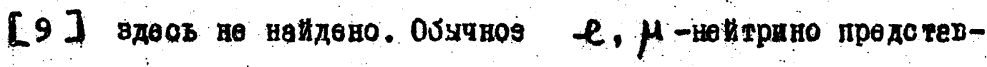

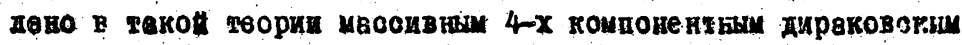

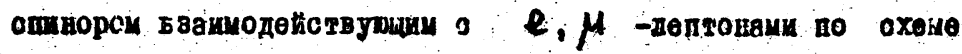
Ведъдовича - Мухауда - Конотнакопо [I8] Сделаня гокхо по-

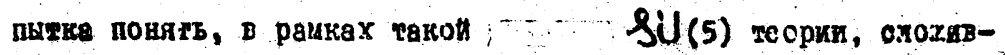

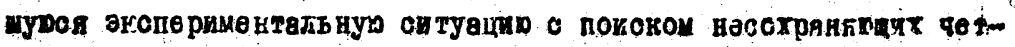

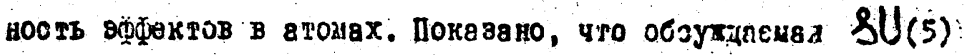


төория в противополодноств обнчния $\mathcal{S U}(5)$ схемви споообна

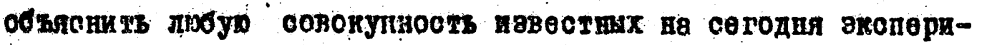

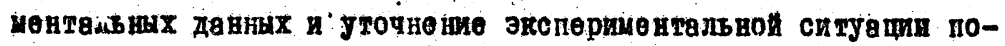
могет фиксировать боде日 точно линь өе иудь типлетныи состав.

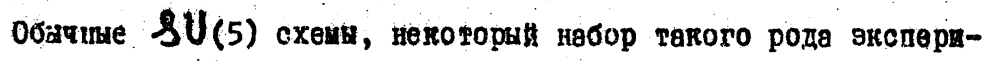

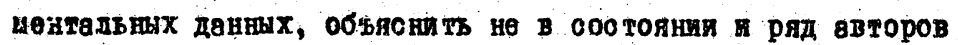
[I4] әта трудность ваотевила усонінтвея в прввильности св-

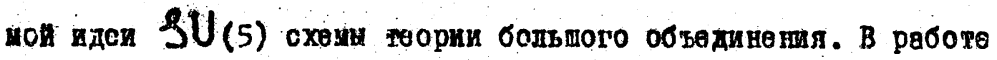
иосдедованы төкке некоторые встрофизијеские сдедствй всищитотически овободнон $S U(5)$ төории. Нандено, что твкая теория

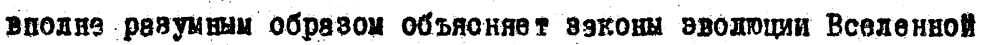
на очев ранвөћ стөдии еө рвзвития $n$, в чвстности, двет торо-

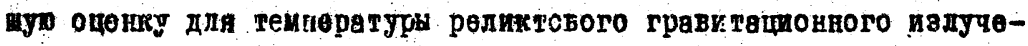
ния. Ивучвется такхе вопрос влияния конечнои часен нейрино на тsкого роде оценку п подазвн, что өспь некотогое несогласие

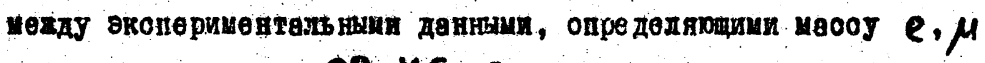

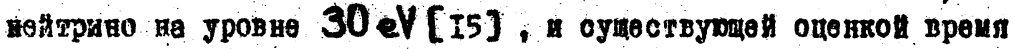

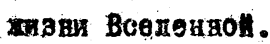

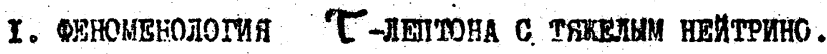

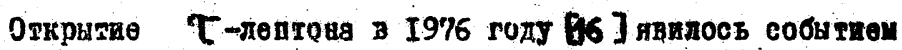

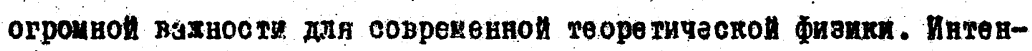

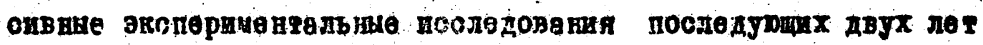

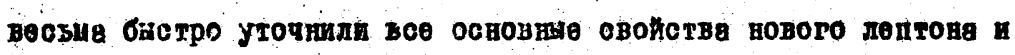

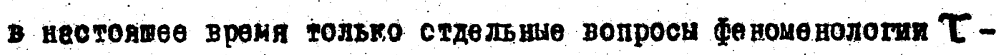
Jептова внанзару төоретические дискуссин. Такии вопросои, D

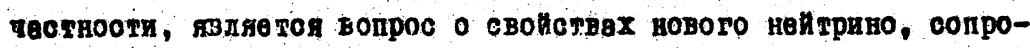
вокдандего $\tau$-лептон. $С$ момента открнтия $\tau$-лептона до наогояного времени две альерна тивне возиовности ("дегкого" [I7] 


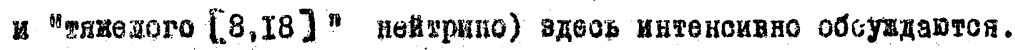

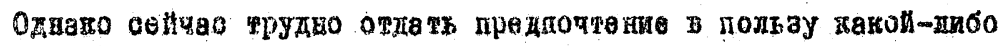

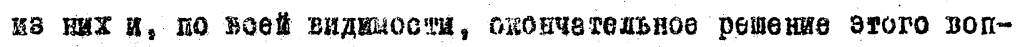

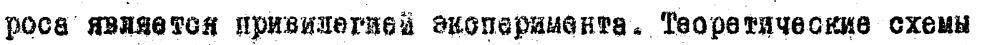

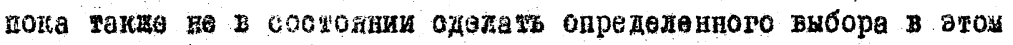
soupoos.

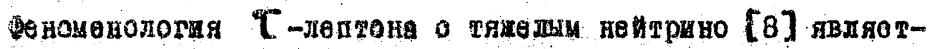

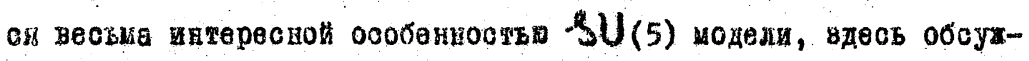

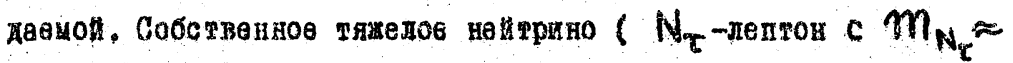

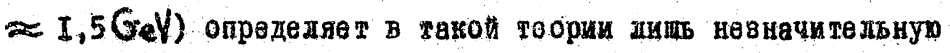
чвсть көнадов рзспвда $\mathcal{T}$-лептоня, в то вреня кев все основ-

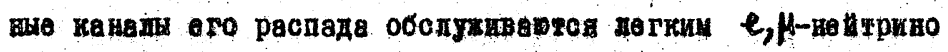

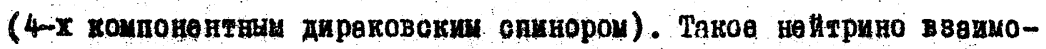
дөногвог - $\ell, \mu$-лептонами по охеме Вельдовита - Нахмјда-

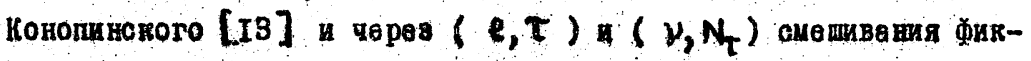

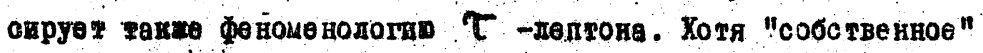

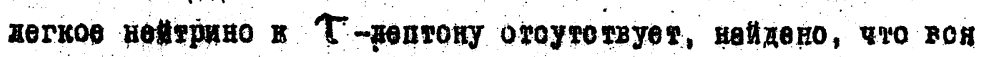

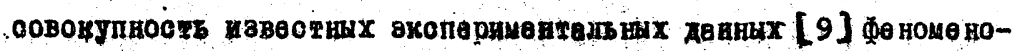

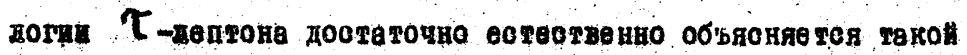

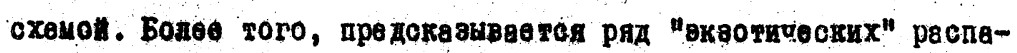

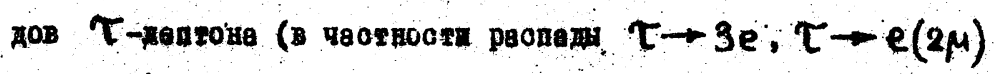

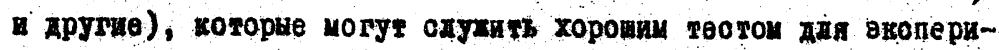

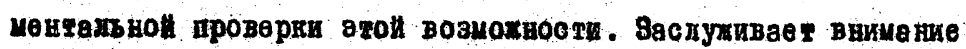

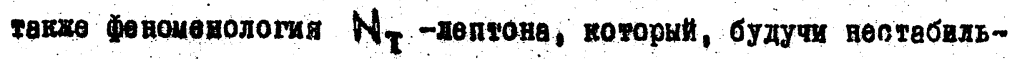

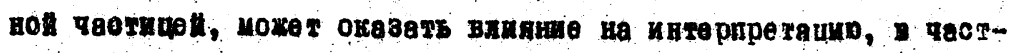

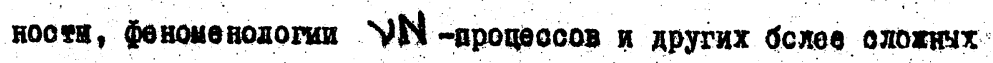
morem:

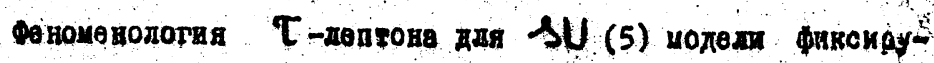

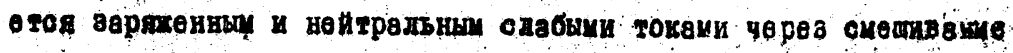


$(e, \tau)$-лептонов а $\left(\nu, N_{\tau}\right)$-неИтрино. Основна нода рас-

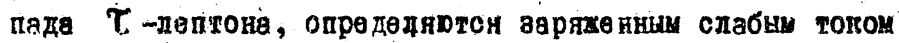

$$
J_{\mu}^{+}=\frac{g}{\sqrt{2}}\left\{\operatorname { t g } ( \hat { e _ { L } , \tau _ { L } } ) ( 1 + | \frac { m _ { \tau } } { m _ { N \tau } } | ) \left(\tilde{\tau}_{L} \gamma_{\mu} \nu_{\tau}-\right.\right.
$$

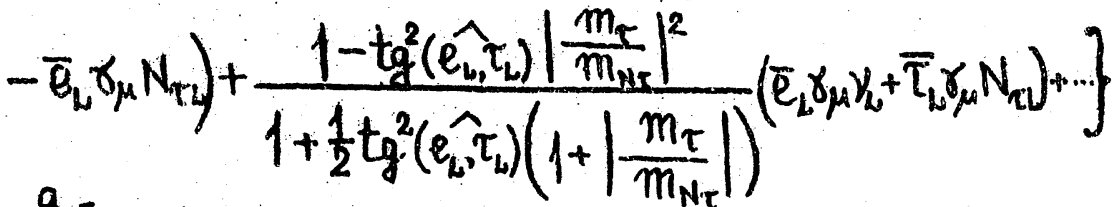

$=\frac{g}{\sqrt{2}}\left[0.44\left(\bar{\tau}_{L} \gamma_{\mu} \gamma_{L}-\bar{e}_{L} \gamma_{\mu} N_{\tau L}\right)+0.9\left(\bar{e}_{L} \gamma_{\mu} \nu_{L}+\bar{\tau}_{b} \gamma_{\mu} N_{\tau L}\right)+\cdots\right]$

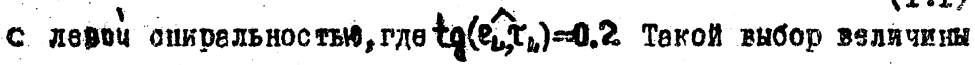
$\left(e_{l}, \tau_{l}\right)$ ометивания явднется вдөсь, практически, мегоямально допуо тимым, ограничивая, такин обрадом, минимедьное врекя

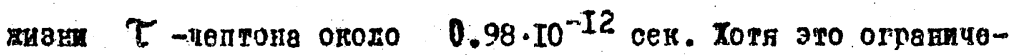

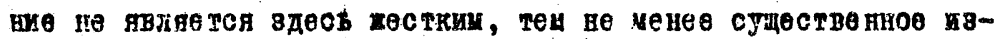

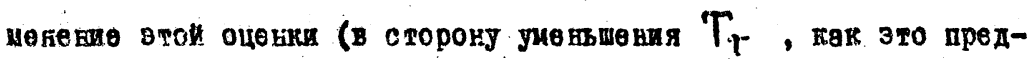

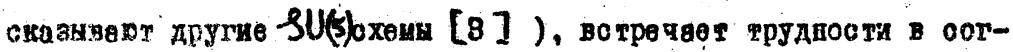

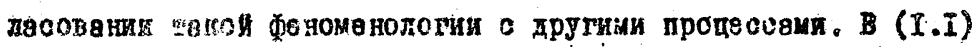

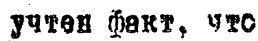

$$
\operatorname{tg}\left(\hat{v}_{L_{1}}, N_{\tau L}\right)=\left(\frac{m_{\tau}}{m_{N_{\tau}}}\right) \operatorname{tg}\left(\widehat{\hat{v}_{L}, \tau_{L}}\right)
$$

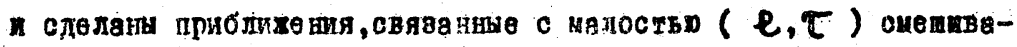
пия. Саетиввние $(\mu, f)$-лептонов (кан $(b, d)$-кевргов) =

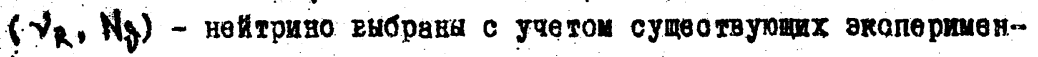

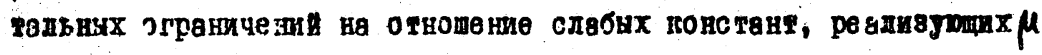
- $\beta$-pacnsд

$$
[\sigma(\beta) / \sigma(\mu)]=1.003 \pm 0.004
$$


$-10-$

ЗдесБ, для $(\mu, \phi)$ посдедоватөльноств $\left(\bar{\nu}_{R} \gamma_{\mu} \mu_{R}\right)$ - ток доставлөн, практичеоки, бөя пвменөвия

$$
J_{\mu}^{t}=\frac{g}{v_{2}}\left(0.99 \bar{\gamma}_{R} \gamma_{i} \mu_{R}+0.14 \bar{\gamma}_{R} \gamma_{\mu} \hat{\gamma}_{R}+\cdots\right)
$$

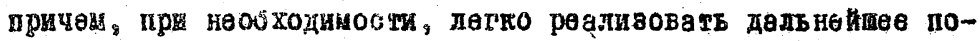

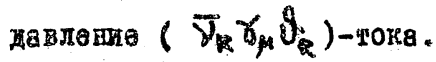

Экзопически рөспеди $\tau$ - нептоне фиксирутоя нентральEWH TOTOM

$$
\begin{aligned}
& d_{\mu}=\frac{g}{\cos \theta_{W}}\left[\left(\frac{1}{2}-\sin ^{2} \theta_{w}\right)\left(\bar{e}_{L} \gamma_{\mu} e_{L}+\bar{\tau}_{L} \gamma_{\mu} \tau_{L}\right)-\right. \\
& \left.-\sin ^{2} \theta_{W} \bar{e}_{R} \gamma_{\mu} e_{R}-\frac{1}{2} \operatorname{tg}\left(\hat{e}_{R} \tau_{R}\right)\left(\bar{e}_{R} \gamma_{\mu} \tau_{R}+\cdots\right)+\cdots\right]= \\
& =\frac{g}{\cos \theta_{W}}\left[0.29 \bar{e}_{L} \gamma_{\mu} e_{L}-2.2 \cdot 10^{-2}\left(\bar{e}_{R} \gamma_{\mu} \tau_{R}+\cdots\right)+\cdots\right](\mathrm{T} .5)
\end{aligned}
$$

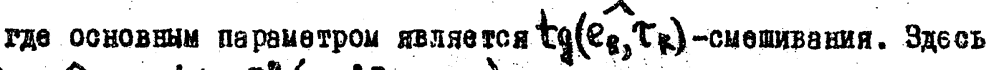

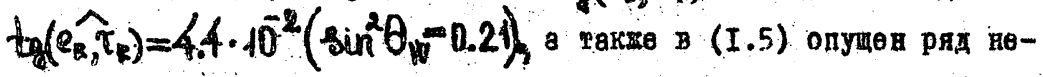
оущественитх членов, Овяввних с мапость этого смешивания.

Выоор такои ведичины угда $\left(e_{R}, \tau_{R}\right)$ - сиениввния внооит примесз правых токов $\& \quad \tau \rightarrow \ell+2 V$ распад на јровне I\% и обеспечи-

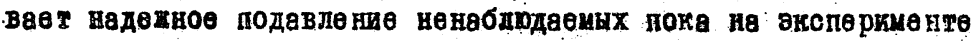
әквотдеских распвдов $\tau$-лептона. Кочөчно, под вдиянеи экспериненте эта оденка нотет быть ивменена. Сушествуйия сөичас әксперименталь ные ограничения укавываут тин, пто $\operatorname{tg}\left(\hat{e}_{R}, \tau_{R}\right)<$ $<0.2$, хотя, по всеи видимости, әтв ведичин не мохет бить рөализована, так как противоречия $V$ - $А$ вавимоденствио $\tau$-лептона $\circ \quad \gamma$-нентрино. Изиенение утлв $\left(\ell_{k}, \tau_{k}\right)$-смевивания, для даннон $S U(5)$ молели, контролируется подгояочним

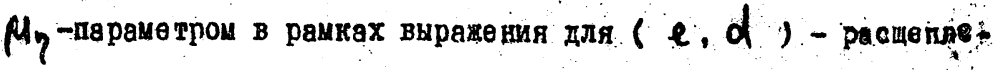
mก Mace 


$$
\frac{m_{d} / R-m_{e}}{m_{\tau}}=\operatorname{tg}\left(\hat{e}_{R}, \tau_{R}\right)\left(\operatorname{tg}\left(\hat{\left.e_{L}, \tau_{L}\right)}-\frac{\mu_{n}}{m_{l}}\right)\right.
$$

Baхнu, однако, әдеоз являетон факт сутествования тактх процессов (экзотичеоких распадов $\boldsymbol{\tau}$-дептона), которне отрого

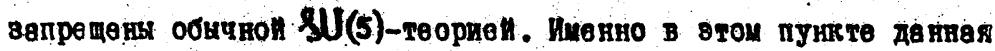
фөномөнология $\tau$-лептона отличветов ог предскавани других SU(5) $\operatorname{cxeu}[3]$.

Ниже феноменология $\boldsymbol{\tau}$-јептона будет представлена, считая вирадения (4.I) и (4.5)фиксированьии. Цель данного уәдошения покезать, что оутөствуюиие в настоящео время этспериментальные двніке по феноменологи $\boldsymbol{\tau}$-лептоне ие противореуат охөне, в ноторой "собслвенное" легнов нейтино к $\tau$-лептону отсутствует. Tакая схемя не нерушвет общепринятон $\boldsymbol{\tau}$-феноиянологи, в төкке предсказывает весвме интересни оледствия, В честности сунествовани, так называеинх, эхвотически процеосов (распадов $\tau \longrightarrow 3 е(e L \mu)$ п пругих), готорыо пока но оснарутены.

Описание фөноненология $\tau$-дептоне пачнен о $\tau \rightarrow V+X$. распадов. Основне раопады. $\tau$-лептонв, в әтон охеме, проиоходит по канвдан $t \rightarrow e+2 \nu$ и $t \rightarrow \mu+2 \nu$. Рвспал $t \rightarrow e+2 \nu$ полкоспьо аналогичен. $\mu$-распаду, 0 поправкои только ва $m_{\mu} / m_{\tau}$ - отнотение гасс. Этот валны факт ин в дальнейөи попольвуен, Стандервне вычиоления нири рөспадв $\tau-e+2 v$

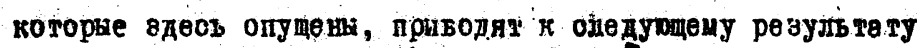

$$
\Gamma_{\tau \rightarrow e+2 \gamma}=\frac{2\left(\alpha^{2}+2 \beta^{2}\right) m_{\tau}^{5}}{192 \pi^{3}}
$$

где найденнье, олөдуя (I.I) и (I.5), $\alpha$ и $\beta$ коэффишиенты 
$d=\frac{0.9 \cdot 0.44 g^{2}}{2 \cdot 4 \cdot m_{w}^{2}}$

$$
\beta=\frac{2.2 \cdot 10^{-2} g^{2}}{2 \cdot 4 \cdot\left(m_{2} \cos \theta_{w}\right)^{2}}
$$

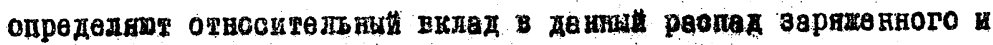

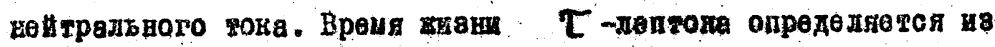
оревневия (I.7) о $\mu \rightarrow e+2 y$ шириво раовада

$\prod_{\mu \rightarrow e+2 \gamma} \frac{2 \alpha_{1}^{2}}{192 \pi^{3}} m_{\mu}^{5} ; \quad \alpha_{1}=\frac{0.99 \cdot 0.9 q^{2}}{2.4 \cdot m_{w}^{2}}$

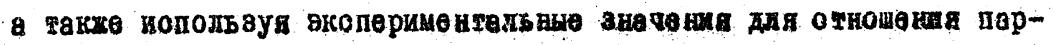
цивльнах чирни

$$
b_{e}=\frac{\Gamma(\tau-e+2 \nu)}{\Gamma(\tau-b c e)}
$$

в вренена тизи $\mu$-иезона $\left(T_{\mu}=2.2 .10^{-6}\right.$ оек). онончвтөльно цолучаеи, что вреия вивни T -дептона

$T_{T}=\left(\frac{\alpha_{1}}{\alpha}\right)^{2} \frac{1}{1+2(\alpha / \alpha)^{2}}\left(\frac{m_{\mu}}{m_{T}}\right)^{5} T_{\mu} \cdot b_{e}=0.98 \cdot 10^{-12}$

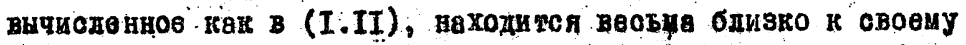

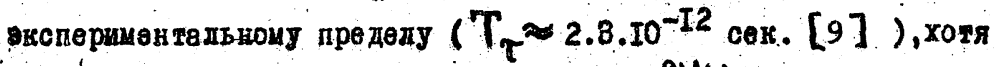

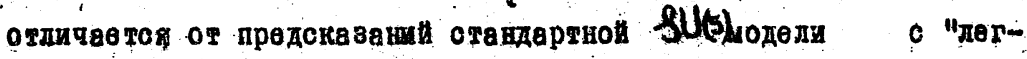
каи" нентрино, тде $T_{\tau}=2.8 .10^{-13}$ сек. опнаго шы не видик в дтом пункт недостатка $\mathcal{S U}(5)$ модөли; вдесь обсухдаеуон. Orспериментальнов подтверждения находит төкхе, вычислевное следуя (I.I) и (I.5), отношение пврциадвных мирин распвда

$\tau$-лөптоне на $\ell, \mu$-лептон

$$
\frac{\Gamma(\tau \rightarrow \mu+2 \nu)}{\Gamma(\tau \rightarrow e+2 \nu)} \approx 1.1
$$

Совпадение о әксперинентвль ным внвчением (I.06 $\pm 0 . I)[9]$ в предөлах ошибок. В целом наңдено, что распад. $\tau$-лептон пе схөмө $\tau \rightarrow \nu+X$ выдержан в достаточно хоропеи согдвоии о эконо- 


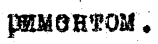

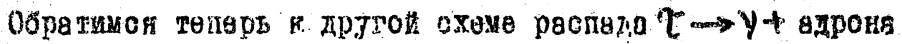

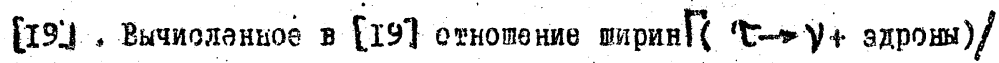

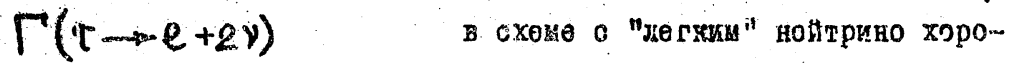

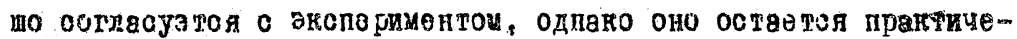

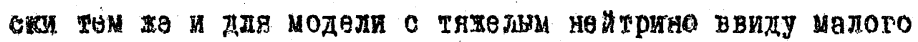
$(\&, d)$ - сиошивания. В зтой сзязи ацесь такве найдано пол-

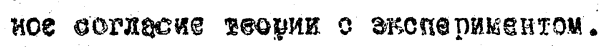

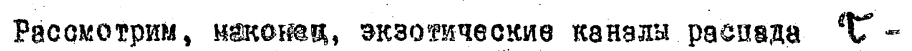

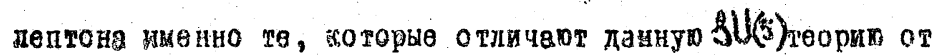

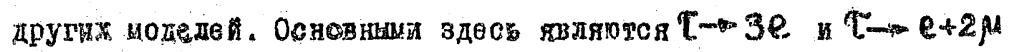

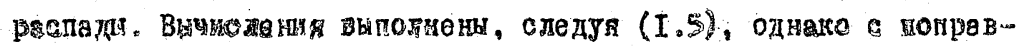

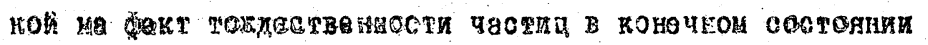

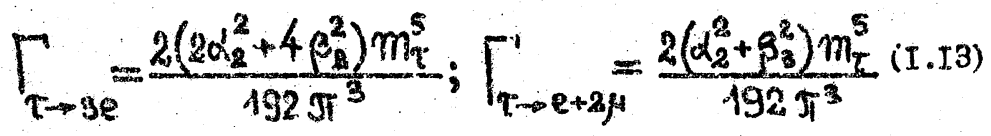

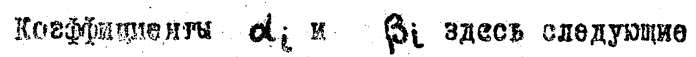

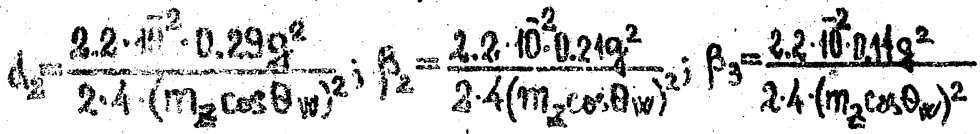

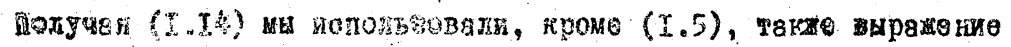

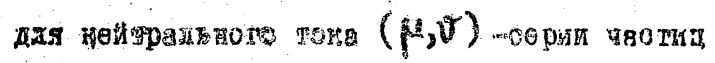

$J_{\mu}=\frac{g}{\cos \theta_{w}}\left[\left(-\frac{1}{2}+\sin \theta_{W}\right) \bar{\mu}_{k} \gamma_{1} \mu_{R}+\left(\sin ^{2} \theta_{W}-\right.\right.$
$-\frac{\left.\sin ^{2}\left(\mu_{\omega_{2} \theta_{L}}\right) \bar{\mu}_{L} \gamma_{\mu} \mu_{L}+\cdots\right]}{2}=\frac{g}{\cos \theta_{w}}\left[-0.29 \mu_{R} \gamma_{\mu} \mu_{R}-0.14 \mu_{L} \gamma_{\mu} \mu_{L}+\cdots\right]$ где прння то, что $\sin ^{2}\left(\mu_{i}, \theta_{i}\right) \approx 0.14$, xогя для этопо фак-

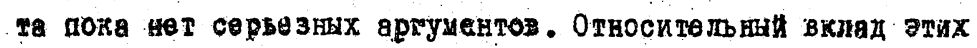

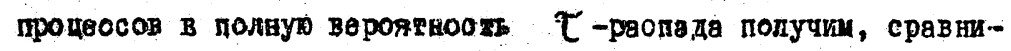




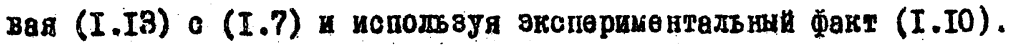
тогда адесь имеси иростые оценка

$$
\begin{aligned}
& \frac{\Gamma(\tau \rightarrow 3 e)}{\Gamma(\tau \rightarrow \text { lce })}=\frac{2 \alpha_{2}^{2}+4 \beta_{2}^{2}}{\alpha^{2}+2 \beta^{2}} \frac{\Gamma(\tau \rightarrow e+2 \nu)}{\Gamma(\tau \rightarrow \text { bce })} \approx 1.7 \cdot 10^{-2} \% \\
& \frac{\Gamma(\tau \rightarrow e+2 \mu)}{\Gamma(\tau \rightarrow \text { bce })}=\frac{\alpha_{2}^{2}+\beta_{3}^{2}}{\alpha^{2}+2 \beta^{2}} \frac{\Gamma(\tau \rightarrow e+2 \nu)}{\Gamma(\tau \rightarrow \text { bce })} \approx 0.5 \cdot 10^{-2} \%
\end{aligned}
$$

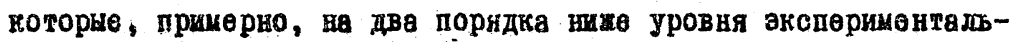
щнх ограничени [9]

$$
\frac{\Gamma(\tau \rightarrow 3 e)}{\Gamma(\tau \rightarrow b c e)}<1 \%
$$

Несокненно, однано, что поиск этих продеосов крайне вахен, тап пак они явдяютоя отаичитель ной чертон феноменологии

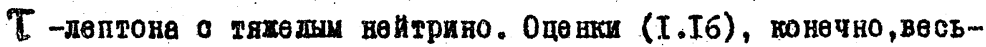
ме приблиненян, однано нулевон вероятност атих процессов бать не нотет. Нудевое $\left(\cdot e_{2} \tau_{k}\right)$ - снешивание противоречит, сдедуя (I.6), необходпмои ведичине ( $e, d)$ )-раодепления.

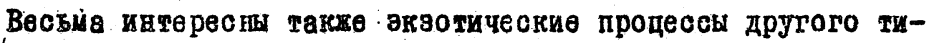

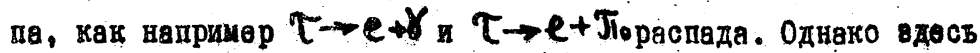

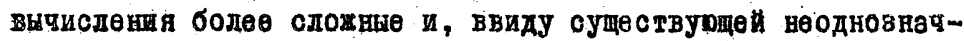
вости в опредедении параметров модеди, век смысла покв проводать вХ полном обзөме. Полезно лишь ограничиться неготорыми оцевками. Так, нвпринер, по поводу $\tau \rightarrow e+\gamma$ распадв мохно предподагать, уто такои распад по оравненио о распадои $\tau \rightarrow e+2 \nu$ будет подавдөн больще төм $\alpha$ - pas

$$
\frac{\Gamma(\tau \rightarrow e+\gamma)}{\Gamma(\tau \rightarrow b c e)}<\alpha \frac{\Gamma(\tau \rightarrow 2 \nu+e)}{\Gamma(\tau \rightarrow b c e)}<0.1 \%
$$




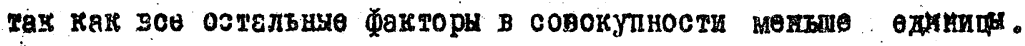
Экспөрвиянтальное ограниченне $(<2.6 \%$ [9] $)$ примерво на поря-

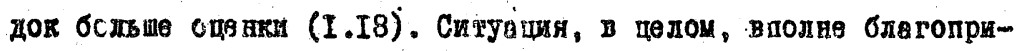
ятная.

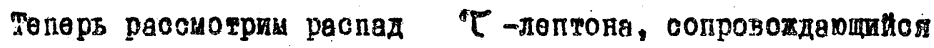

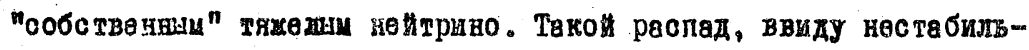

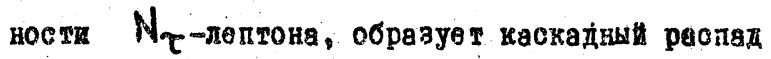

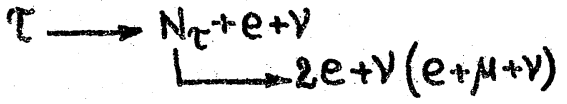

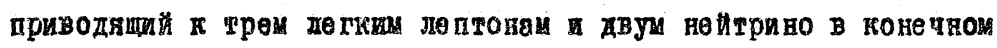

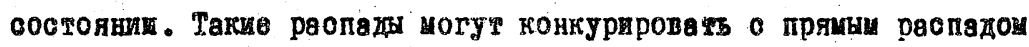
$\tau \rightarrow 3 e(\mu+2 e)$ и отот бакт следует иметь в виду при обработко

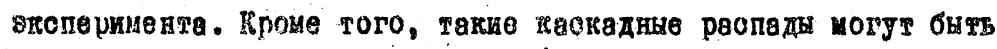
интересвы при кнтерпреташи VN. процессов.

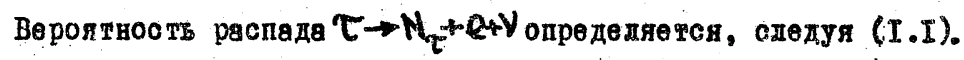

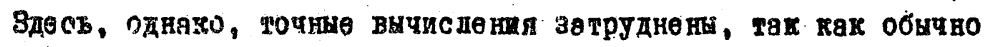

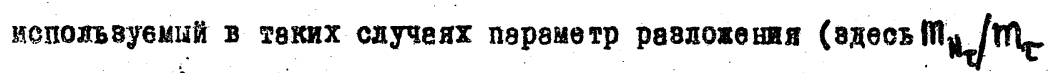

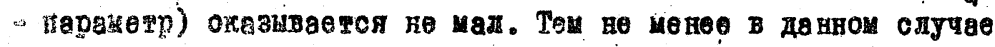

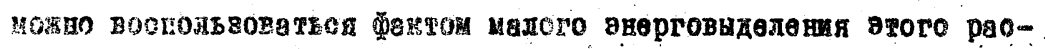

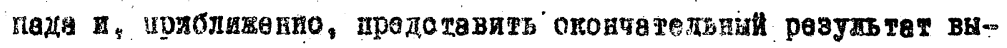

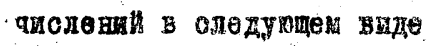

$$
\Gamma_{\tau \rightarrow N_{\tau}+e+\nu}=\frac{2\left(\alpha^{2}+\sigma^{2}\right)}{8 \pi^{3}}\left(m_{\tau}-m_{N_{\tau}}\right)^{5}
$$

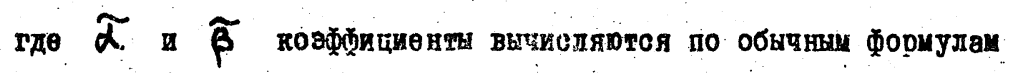

$$
\tilde{\alpha}=\frac{0.9 \cdot 0.9 \mathrm{~g}^{2}}{2 \cdot 4 \cdot \mathrm{m}^{2}} ; \quad \tilde{\beta}=\frac{0.9 \cdot 0.98 \mathrm{~g}^{2}}{2 \cdot 4 \cdot \mathrm{m}_{W}^{2}}
$$

Теперь, сравнивяя (I.7) и (I.20), а такто используя (I.IO), дегко опредөлить относительнуо вероятность этого канада рас- 
пада в полной феноменологии $\boldsymbol{\tau}$-депуона

$$
\begin{gathered}
\frac{\Gamma\left(\tau \rightarrow w_{r}+e+\nu\right)}{\Gamma\left(\tau-\varepsilon_{c}\right)} \\
=24 \frac{\tau^{2}+\bar{\beta}^{2}}{d^{2}+\beta^{2}} \cdot\left(\frac{\left.m_{r}-m_{n}\right)}{m_{t}}\right) \cdot(1 z \%) \approx 0.1 \%
\end{gathered}
$$

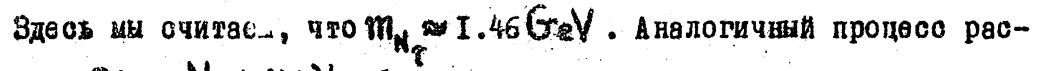
пада $t-N_{\mathrm{t}}+\mu+V$ будвт адесь примерно на порлдок подав-

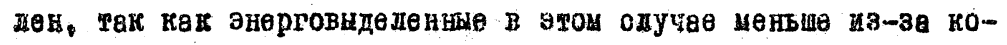
нөчно насен

$$
\frac{1\left(t-\mu_{\tau}+\mu+\nu\right)}{T\left(\tau-R_{c e}\right)} \approx 3 \cdot 10 \%(1.25)
$$

Иатересно такне оденить относктельнуг вероятнасть распадов $\mathrm{N}_{\tau}-$ дептона по каналаи ( $2 e+\gamma)$ и $(e+\mu+\nu)$, которые для этого лептока являются основными. Вероятности рвспада $N_{T}$

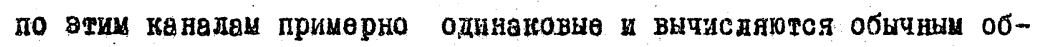

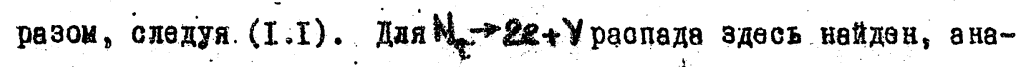
логичны $(I .7)$, рөзудьтат

$$
\Gamma_{n_{\tau} \rightarrow 2 e+\gamma}=\frac{2\left(\alpha^{2}+f^{2}\right)}{192 \pi^{3}} m_{N_{\tau}}^{5}
$$

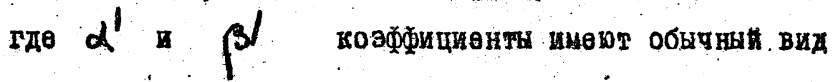

$$
\alpha^{\prime}=\frac{0.44 \cdot 0.9 q^{2}}{2 \cdot 4 \cdot m_{W}^{2}} ; \quad \beta^{\prime}=\frac{4.4 \cdot 10^{-2} \cdot 0.9 q^{2}}{2 \cdot 4 \cdot m_{W}^{2}}
$$

Проводя оравнеян (I.25) и (I.8) квходин, что вероятности распада $\tau$-лептона по канаду $(\ell+2 \gamma)$ и $N_{T}$ пептона по канеду $(2 e+y)$ примерно равн. Такая анвлогин иохет быть замөчена и для других канајов распада. Основнваясъ на атой аналогии можно считать, что по всей видимозтн будут рвви и 


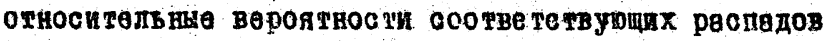

$$
\frac{\Gamma\left(N_{\tau}-2 e+v\right)}{\Gamma\left(N_{\tau}-6 c e\right)} \approx 0.17
$$

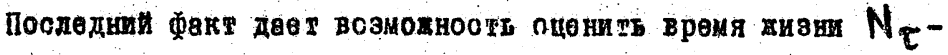
лептона весьма простик способом

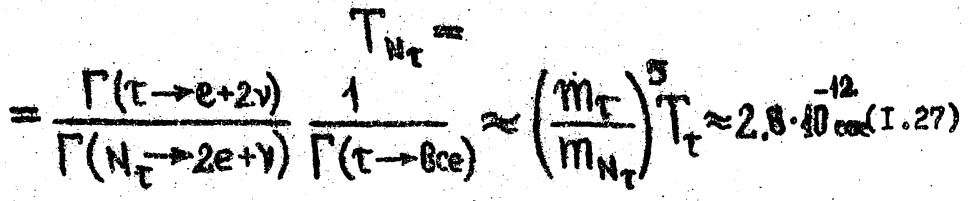

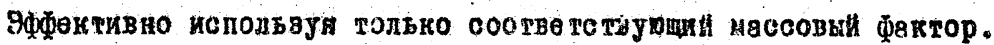

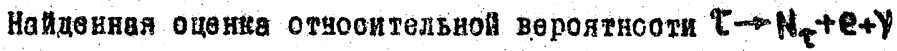

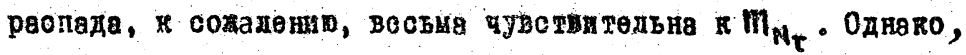
охидать уиеньшенй веронтности этого распада нет серьевњх чричин, так как јвеличения

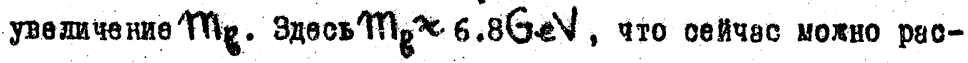
сиатривать как зерхни предел для өтой мессы. В такои случве

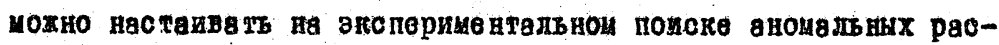
пвдов $\tau$ - лентонв,
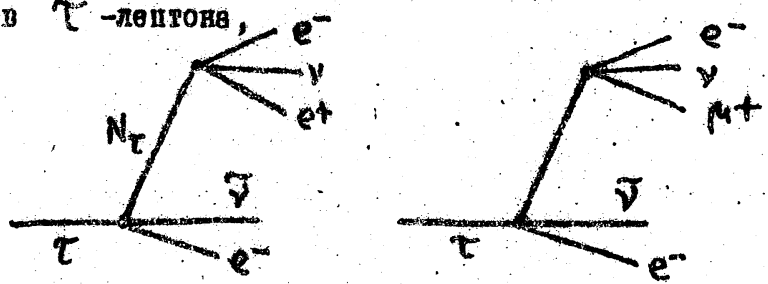

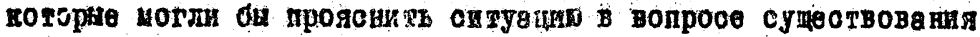

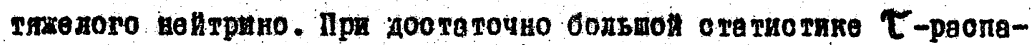
да такие процөоси, следуя (1.22), доншн бить наидени.

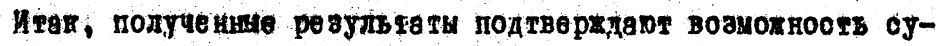

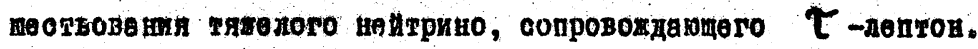

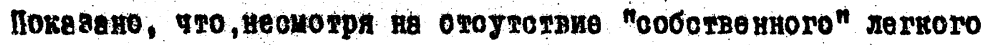

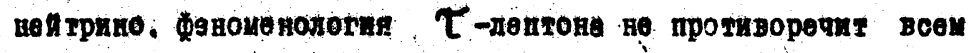


доститнутым вө сөгодня экспериментальным двнным. Кри тичөски-

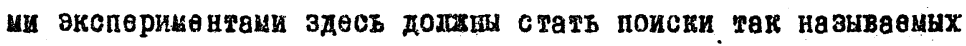
вномальнах и әквотичеотих распадов $\mathcal{T}$-дептона. По всен вири-

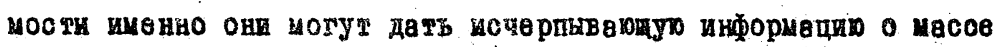
$N_{\tau}$-иейтрино.

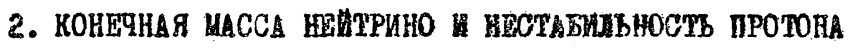

Пробнеме конечной иассн неитрино, так ше как проблема нөйтринжа осцидлици, в последнео время интенсивно обсушдавтся в работах иногих авторов [20]. Интерео ж этим проблемам обуславливаетсл вовмохвы открытиеи нового $\mathrm{N}_{\tau}$-нейтино, а төкше обнадешивапими предскаванияи төории большого обэединөвия, где дептонно феноменояогих с массивными нентрино отдаөтся предпочтение. Попа эксперинантальная ситуащи адеоь оста-

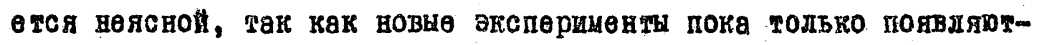
оя, а теретичөская интерпретаџия отарых өкопериментальных

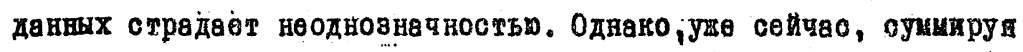
рөзудьтати төоретически и энспериментвдьних работ, по всөн видииости, мохно считать доквзанным факт нөнулево цасси $\ell$, $\mu$-нейтрино, хотя өө величина покв остается нөясной. В приншия вдесь появилась интересная возмохность [6] обБяони ть понөчное время жизни протона и ненудевуо иясоу нентрино, как разные проявления одной и тон хе сушности, а именно факта суцөствования в төории оупөртящелых, төк называөмых, дөптокварк

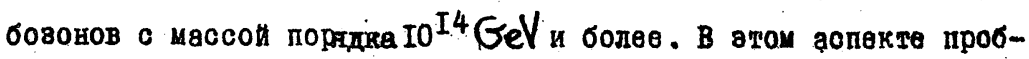
дөма конөчноһ̆ массы нейтрино прпобретает особур өвтувдвность. төк как мохет представить веромне артумент в поддеркку төо-

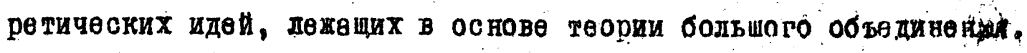


Однако, в атон сдучве, $m_{\nu} \leqslant 10^{-8} \mathrm{eV}$. Этот факт обсухдаөтея во инотих работех, однако не очитается общепривнанеки.

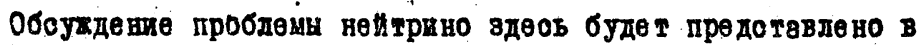
рамках $S U$ (5) тө орин, ивдохөннои в рвботе [7]. Эта төория предспазывает ковечнуо иассу $e, \mu$-пентрино, когорое представлено адеов одни 4-х хомпонөвтни дираковским опинором, взанмодействуоцин о $e, \mu$-лөптоввии по схемө Зөдвдовичв Maxuуда - Kонопинокого [I3]. Такая теория содерхи такхо ряд

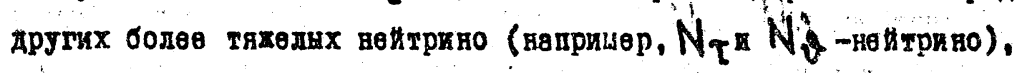
однако послөдняе являртея нөстабильнви чвстицаме и их своһ-

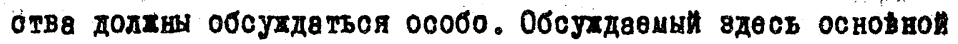

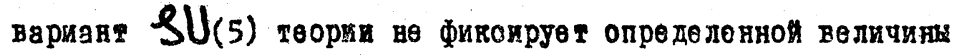
масон $V$-нентрино. Здесь последвяя махет быть производъноһ, отлично ㅇ нуля, величинон и существует подгоночны парамөтр, которын долхөн оогдасовать прөдокаввнил төорни и өксперимента. Однако, возмохна друтая подгонка пвраметров $\mathrm{SU}_{(5)}$ төориг $[6]$, ногде модель предоказывает вполне опредеденно атачение ивсоы $e, \mu$ - нентрино: В таном вариевте SU(5) величина невовмохно. В таком варивнте теорни Факт конечнон чвосу ве трино и иестабиль ность протоня дестко торрелирован-

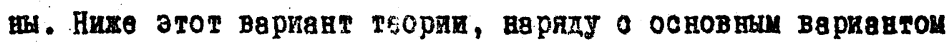
४U(5)-нодеди, будет такев обоушдатъся. SU(5)-төория, в общен сдогности, обтединяет 5-яенитрельпих дептонов, один иа которих воегдв явдяется суперэяхелы $\left(m_{Q} \approx\right.$ I0 $\left.{ }^{4} \mathrm{GeV}\right)$. Послөднй ве участвует в слабом вваниоденствии, в то время как 4 других нећтрино сопровохдарт сдвбне распади соответствуюии лептонов. Сповтанное нерушенте 
синиетрии приводит к их взвинвону перемешивавир, так как

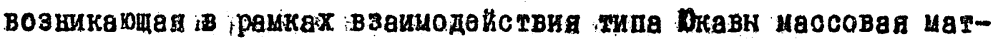
рнца не явдиетоя диаговвльноң

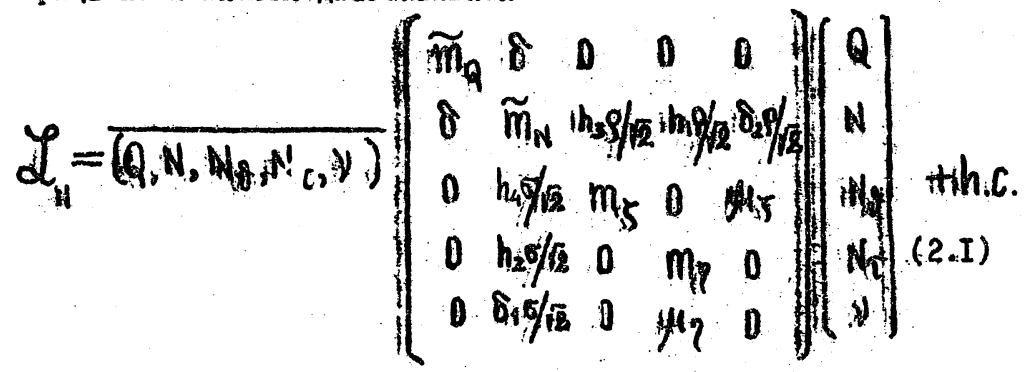

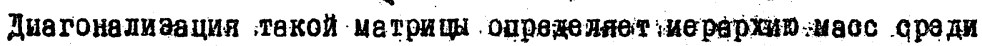

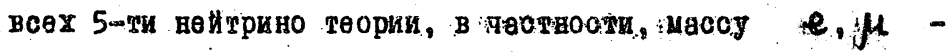
нейрино, которое здесь является наиболеө легкон чвсгицеи. Дөтериинант матрицы (2.I), которын ле тко вычисдяется точно $\operatorname{det} m=-\tilde{m}_{Q}\left[\left(\frac{h_{3} p}{\sqrt{2}}\right) \mu_{r}-m_{\zeta}\left(\frac{\delta_{2} \rho}{\sqrt{2}}\right)\right]\left[\left(\frac{h_{2} \sigma}{\sqrt{2}}\right) \mu_{y}-m_{g}\left(\frac{\delta \sigma}{\sqrt{2}}\right)\right]$ позволяөт, в общем видө, сдөлать ряд вакдрчөнин о спектре масо төноН теории, В пастности; весема төсно финсировать нво-

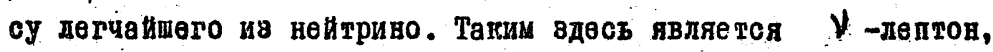
вваимодейстьуюшин о $e, \mu$-дептонами по охемө Зөдъдовиपв-Махмуда-Конопинского [IЗ] . Оценка мвсоы $\vee$-неН трино опредөляется вьрахениеу (2.2)

$=\frac{1}{m_{i}}\left(\frac{m_{c}}{m_{N_{s}}}\right)\left(\frac{m_{\eta}}{m_{N_{\tau}}}\right)\left[\frac{h_{s} \rho}{\sqrt{2}} \frac{\mu_{r}}{m_{r}}-\frac{\delta_{2} p}{\sqrt{2}}\right]\left[\frac{h_{2} \sigma}{\sqrt{2}} \frac{\mu_{\eta}}{m_{l}}-\frac{\delta \sigma}{\sqrt{2}}\right]$ өсли считать, что спектр мөос остальных лөптонов извөстен. Именно в этом пункте, в оценке массы $N$-лептона, две возиок-

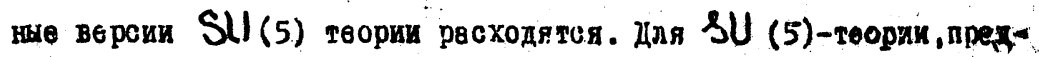

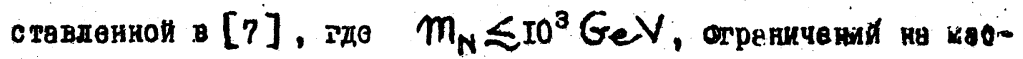




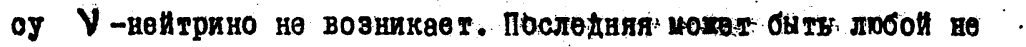

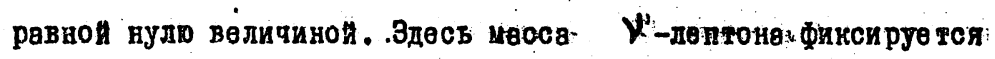
обрапониеи в нуль равенства (2.3)

$$
\frac{\delta_{2} \rho}{\sqrt{2}}=\left(\frac{h_{3} \rho}{\sqrt{2}}\right) \frac{\mu_{5}}{m_{5}}
$$

पто даөт возиохность получить, в рамках основного вариантв гөории, доствточно малуо величину массы $e, \mu$-вейриво (порядкв 0.IeV). Ясно такде, что нулөи такая масса бить но цовет, так как о учвтои радияционак попрввок условия $(2,4)$. нө будет обеспечиввть равенство нуло соответо твующөго детер-

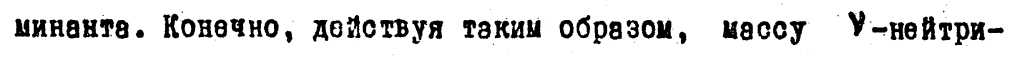
но мохно сделать сколь угодно малои, обеопечив конпөнсвщи өө величине в $n$-приблихеви. На әтои пути нохно получить согласия с әкопериментом [I5] прөдскөзанин даннои \&U (5) төорин.

Однако, оуцествует другвя возмохность $S U(5)$ төорих [6], sогда масов $N$-дептона порядка $\mathrm{IO}^{\mathrm{T} 4} \mathrm{GeV}$. В рвмках такои

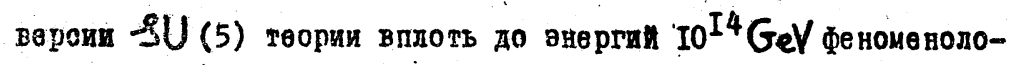
Гия слабих взаимодењствић определяетоя только 4-ия звряве ни-

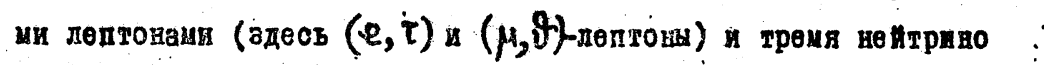

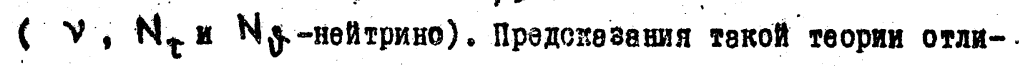

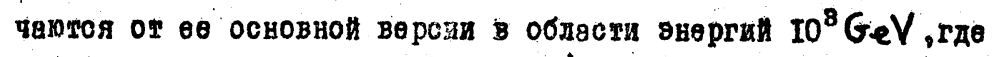
иогли ом оудествоватв $E^{-}$и $\mathrm{M}^{+}$-лептони и сопроводдвриев их $N$-неитрино, Версия $S U(5)$ төории о тявелым $N$ нөй трино интересна теи, что адөсз иясса $V$-већтрино огреничена сверху

$$
m_{v} \leqslant \frac{m_{W V}^{2}}{m_{x, y}} \approx 10^{-3} \mathrm{eV}
$$


превзоИти әту оценку не представляется возиодним. Вахно огІтить такще, पто в такои варианте $S U(5)$ төории ненудевая 1008 већ̆трино и. конечное вреия хизни протонв

$$
T_{p} \approx\left(10^{3}-10^{4}\right) \frac{m_{x, y}^{4}}{m_{p}^{5}}
$$

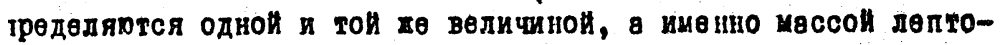

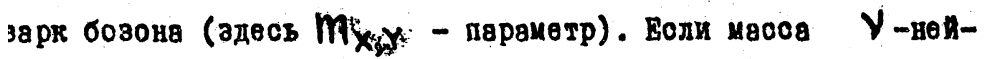
рино дөћстви төльно окөшетея' таного порядка: (ряд экоперименכв [20]? такзе настаивает не этон вөличине), то әтот факт буэ т серьезной поддерхкон в пользу версии $S U(5)$ чодели о тяхе-

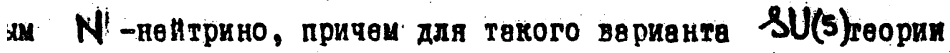
охнс будет сдедвть вполне определеннне предоказаня по повоу Факте нестабильности протона. В әтом смысле әксперименты - определенио масов $У$-неитрино краине актуальн, так кал - всей видимости, әксперинент по определенио врененг хиян ротонв более неоднозявчныи, если учесть тот фект, что легко

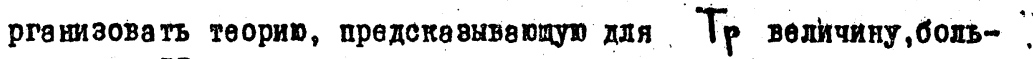
yั чөм $10^{33}$ дөт.

Спектр иасс оствдьных нећтрино төкхе весъме интересен, днако өго обсуддение требует болеө полноћ диагоналгваши өтрищы (2.I). Иерархия параметров, определяюших өуу партину, lомогает решить такую задачу, используя приблихенные ме тодн

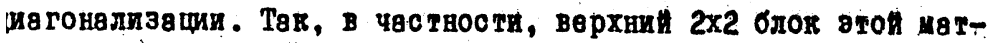
пшы достаточно хороно выделен иерархи параме тров и мохет інть диягоналивован самостоятедьно

$$
m_{Q}=m^{*}+\frac{2}{3} k_{D} s ; m_{N}=m^{*}-m_{B}-s k_{D}
$$


Вдеов $M_{B}$ - автрввочная насса. $B$-мудьтипдета, $S$ - параметр порядкв $10^{I 4} \mathrm{GeV}$. Вахно отметить, что дия В-иудь типлета воегда сумествует весъма точная $S U(3) \times 3 U(2)$ - симметрия, поәтому $E, M$-лептоны в этом иультиплете имерт танже $m^{*}$ масоу. В завкоиности ог принятон версии SU(s)-төории $m *$ параматр монөт быть дибо - $\mathrm{I0}^{\mathrm{I} 4} \mathrm{GeV}$ либо $\mathrm{I0}^{8} \mathrm{GeV}$. На эrou уровне дивгонадивачи $Q$-дептон отделяется и оставнвяея 4x4 матрица

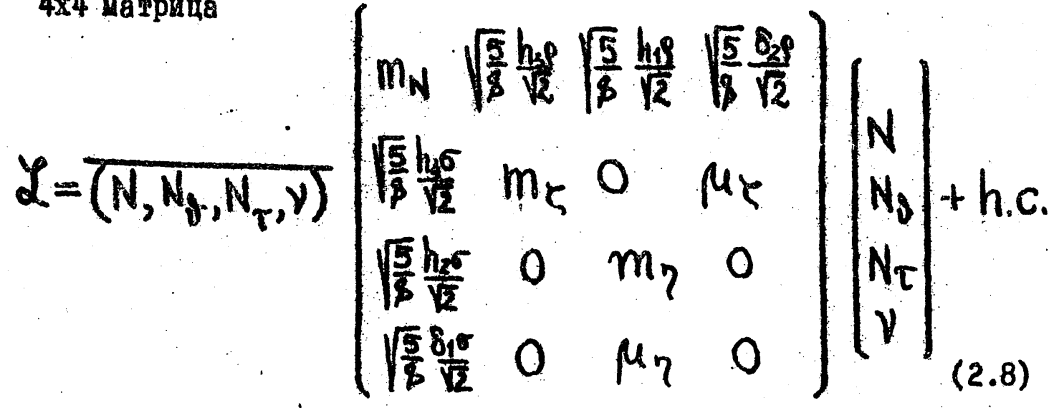

являетоя предметом дальнөйего обсухдения. Продолкая рөдукши анадогичния образом, нохно оценить массы $N_{\theta}$ и $N_{\tau}$-ненитино, считая однвко, что $m_{\tau} / m_{t} \ll 1$. Это ограничени не снихает общности рассмотрення, так как, по всеи видимости, именно әтот сдучан ревдизуется в действтельности . Тогда достаточно просто можно оценшть массу $\mathrm{N}_{\tau}$-дептона, $m_{N_{\tau}}=m_{2}-\frac{5}{8}\left(\frac{h_{1} \rho}{\sqrt{2}}\right)\left(\frac{h_{2} \sigma}{\sqrt{2}}\right) \frac{1}{m_{N}}\left(1+\frac{5}{8} \frac{1}{m_{N}}\left(\frac{h_{3} \rho}{\sqrt{2}}\right)\left(\frac{h_{6}}{\sqrt{2}}\right) \frac{1}{m_{l}}\right)_{(2.9)}$

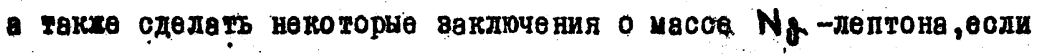
уточна ть $\mu_{\zeta}$-параметр. Одновременно о вырахевием (2.9) опре-

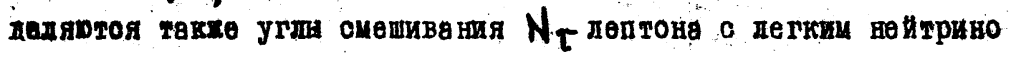




$$
\begin{aligned}
& \operatorname{tg}\left(\nu_{L}, N_{\tau L_{0}}\right)=\frac{1}{m_{N_{\tau}}}\left[\mu_{q}-\frac{1}{m_{N}}\left(\frac{\delta_{1} \sigma}{\sqrt{2}}\right)\left(\frac{h_{1} \rho}{\sqrt{2}}\right) \frac{5}{8}\right] ; \\
& \operatorname{tg}\left(\nu_{R}, N_{\tau R}\right)= \\
& =-\frac{1}{m_{N_{\tau}}}\left(\frac{h_{2} \sigma}{\sqrt{2}}\right) \frac{5}{8}\left[\left(\frac{\delta_{2} \rho}{\sqrt{2}}\right)-\frac{\mu_{r}}{m_{5}}\left(\frac{h_{3} \rho}{\sqrt{2}}\right)\right] \frac{1}{m_{N}} ;
\end{aligned}
$$

вогорые итрарт ватвуо роль в определения феноменологит $\tau$ дептонв. Заметии, что в добои случве $\left(\nu_{k}, N_{i k}\right)$ - сиешивания

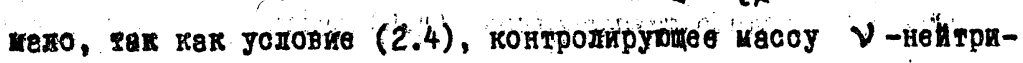

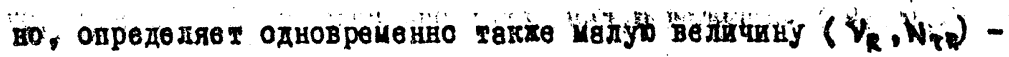

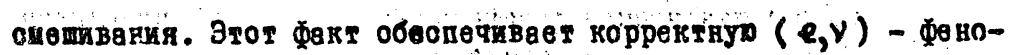

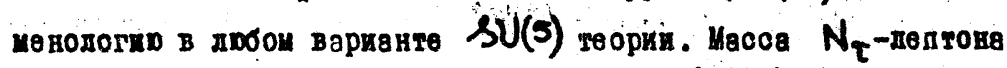

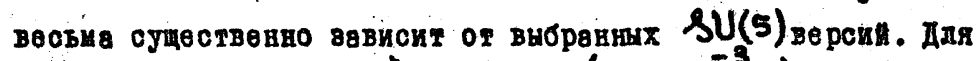
SU(5) верени, тде $m^{*} \approx{ }_{10}{ }^{I 4} \mathrm{GeV}\left(m_{\gamma} \leqslant 10^{-3} \mathrm{eV}\right) \mathrm{N}_{\tau}$ вен тркно не мохег бнть дегким. ЗАесь $m_{N_{T}} \approx m_{T}$. В. оО НОВном В8-

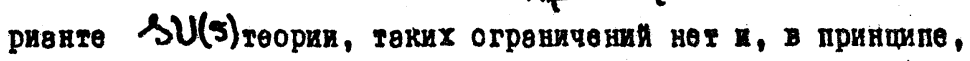
мохно бнло бн построить такхе охеиу $\tau$-феноменодогих $е$

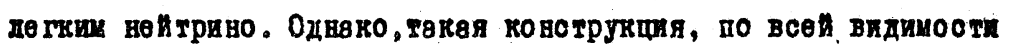
вдесз будет. про тиворечива, гек как трудно на эгои пуги обеопе-

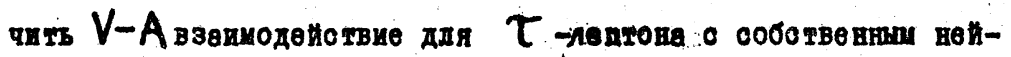
sриіо. ноненодогия $\tau$-лептоне о гяхедыи веитрино адеоз вам көхетея болеө өстественноң и, квх поквзано в работе [8], не тротиворечит оутествуоири сейчас эксперименталь нии давнви.

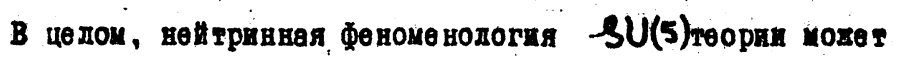

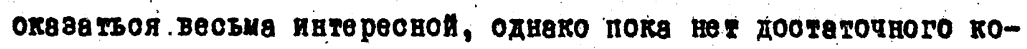
личества әкспериментальных данвх, чуобн однозначно фиксиро-

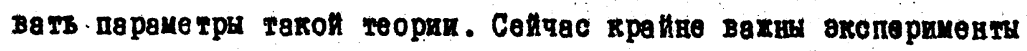

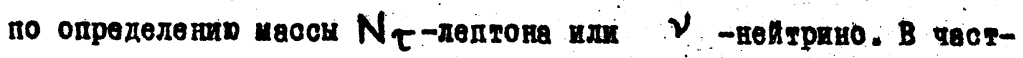

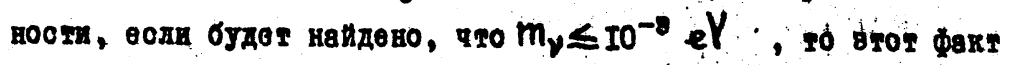


будет такхе вподне доствточни, ччобн фиксироввев SU(5) стөиу

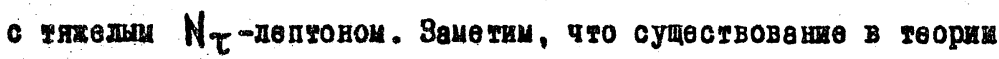

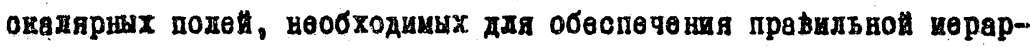

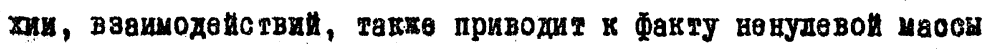
нейтрио. 8деоз $m_{v} \leqslant 10^{-8} \mathrm{eV}$ вовнкаөг во втором поряд-

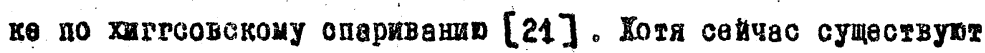

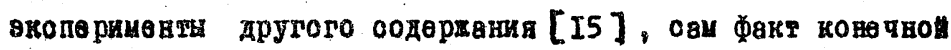

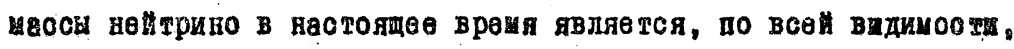

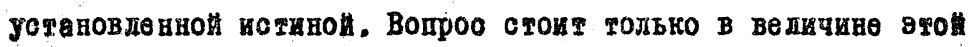

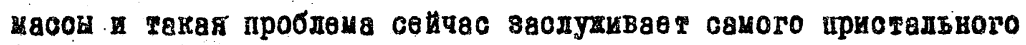
внамакй.

8. ПРОБДЕМА НАРУШЕНИЯ ЧЕТНОСТИ В АТОМНОИ ФИВИКЕ

Уопешное развитие төорни большого объөдинения возродвдо

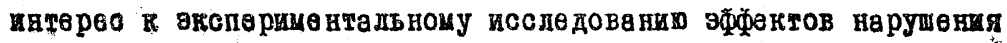
че тности в атоивон фивике. Существоввние таких аффектов предоквзывалось Зедздовичен [22] , впөрвне, в 1959 тоду й впосдедотвии обсухдвдось в ряде рвбот других авторов [з] . В чвстнооти, модель объединенно го вваимодействия Вайберга-Салама достовернооть котороћ подтверждена многими өксперименталь вам фактами, төке предсказывает венудөвур вөличину таного эффекта и, в конечном счөтө, өкспериментальнвя проверка такого рода прөдсказани теории сөйас переросла вадачу первостепеннои Baxroorx.

Энсперименты, однако, оказывапся противоречивыми по свокм предокавания и вплоть до вастоящего врецени, ситуация. как анопе риментөльная, так и теоретичөсквя, остаетея неясноћ. 0о0бө нно несогдасовянными являотся әкспе риментальные предскв- 
звния ведичине эФекта нөсохранения чөтности в тявөлых атомах. Здесь резудь таты одних экспериментов [24] хоропо ооглөоуртся с предсквванияи нодели Ваинберга-Салама, в другк

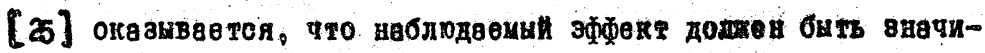
төльно подввлен. Существот така экспөрименты по ed -рассөяниш поляризованных әлектронов [ж]. Вдесз әффөкт наблюдаө тся в полном соответствии с предске за ниями $J U(2) \times L(1)$ - моденв. Төоретическое иоследование әфектов нарушения чөтноот проводитоя не основе эффективного кварк-лептонного лөгранхивна, которын, следуя (2) ], удобно параме тризовать сдедутони

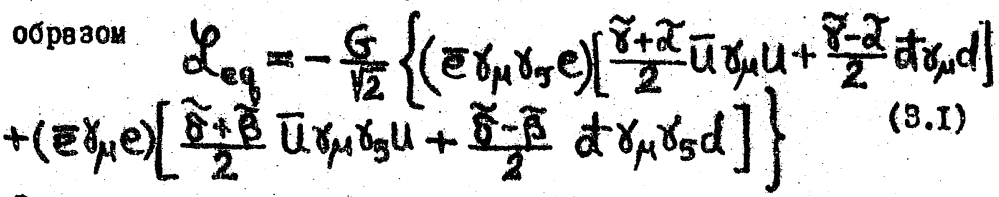

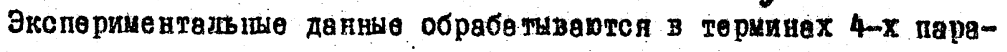

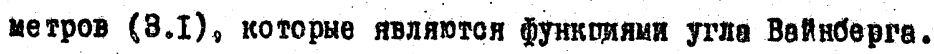

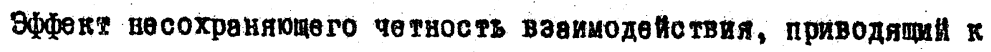
оптическову вращени плостости поляризачии пропориионалеи, тав называемому, "сләбому заряду"

$$
Q_{v}=(A-2 Z) \tilde{\alpha}-3 A \tilde{\gamma}
$$

которыһ, следуя (3.I), определнется тольго $\boldsymbol{X} ; \boldsymbol{\gamma}$-пара ме трани. В (3.2) A и $Z$ - соотве тотвенно, өтом нй номер и

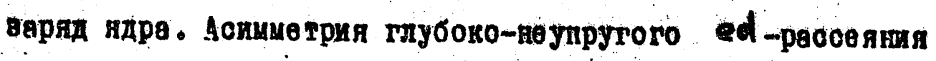
$A(y) / q^{2}=a_{1}+a_{2}\left[\left[1-(1-y)^{2}\right] /\left[1+(1-y)^{2}\right]\right\}$ определяе тея всеии коэффицие нтвии (3.1) и параме гриаоване, одөдуя $(3,3)$, двуія вөличивами $\tilde{a}_{1}=a_{1} / k=\alpha+\frac{1}{3} \tilde{\gamma} ; \quad \tilde{a}_{2}=a_{2} / k=\gamma+\frac{1}{3} \tilde{\sigma} ;$ 


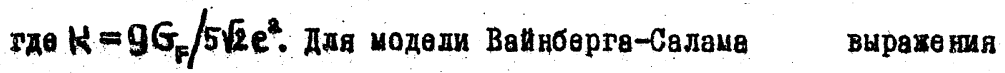

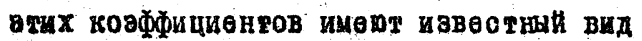

$$
\begin{aligned}
& \tau=-\left(1-2 \sin ^{2} \theta_{w}\right) ; \tau+\frac{1}{\delta} \tilde{\gamma}=-\left(1-\frac{20}{3} \sin ^{2} \theta_{w}\right) ; \\
& \gamma=\frac{2}{3}-\sin ^{2} \theta_{w} ; \tilde{\beta}+\frac{1}{\delta} \tilde{\sigma}=-\left(1-4 \sin ^{2} \theta_{w}\right)
\end{aligned}
$$

и вффенты весьма иувотвитөльны к выбору величины $\sin ^{2} Q_{W}$. дая $S U(5)$ нодеди $\sin ^{2} \theta_{W}=0.23$.

$S U(5)$ - модедь өдиного взаимоденотвия $[I \div 4]$ объединяет ввантовую хромодинамику и $\quad s U(2) \times U(1)$ модөль ВанинергаСадамв в рамках өдиноћ калибровочно группн. Для обычнах ва-

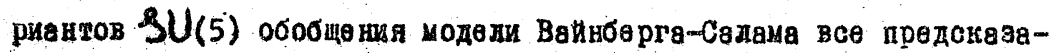
шая өтой модели сохракявтся, хотя, при обработке эксперименгвльных декных, следует использовать другое значени $\sin ^{2} \theta w$. 3дес $\sin ^{2} \theta_{w}=0.21$. Однапо это изиөнение не являетоя патөотвениым, Еоли экспөрименты [24] окашутся невервыни, то

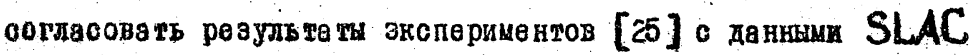
по нөупругому ed-рассеяни в рамках $\$ U(5)$-ноделеи [3] өхатется вөсзия грудно. Этв ситуация звотавида ркд авторов [ [4] отквзатоя ог $S U(5)$ схемн большого объвдинения и иснать выход ия олохившихс труднос тей в болеө сломих ноделях.

Вдесь будет показано, что столь радикальные меры, по отноненио $S U(5)$-гөорий превдевременны. В чвотности, для $S U(5)$ чодели большого объединения, предлогенной в рабоге [2], найдена возмохность [?] дегко разрешить всо возникиие не данном

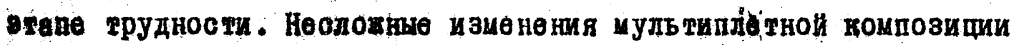
- pamках $3 U(5)$ модеди способны согласовать рөзуло таты әкспориментов [25 7 а данныи SLAC [26] такно весьма өстественным обрввом. Выяснение әкспериментальноћ ситуации для данноћ SU(5)-мөдели оанячает выбор вполне определөнного иудьтиплет- 
вого содерхания.

SU(5)-нодедь, как оне ивдовене в работе [7], согласуетоя тольто с әксперинентани [24] и [26]. Возможноеть изменить өе предсказанд, бөв изменения иуль тиллетного содершания, здеов не пвидека, хотя рөальныя предпосыли для этого суцествурт. При данчои $S U(5)$ комповициц спинорншх мультиплетов "слябыи авряд", по срввненио с модельш Ваннберге-Салама, определяютоя

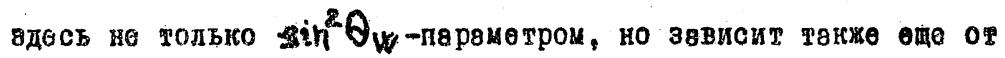
двух доподни төльных парамөтров $Q_{w}=\left[(A-2 X)\left(-\frac{1+C_{L}^{2}}{2}+2 \sin ^{2} \theta_{w}\right)-3 A\left(-\frac{1-C_{\mu}^{2}}{2}+\frac{2}{3} \sin ^{2} \theta_{w}\right)\right]\left(1-S_{(2)}^{2}\right)$ поторно, в принщипе, могли бы иаменить существо деда. Дейетви-

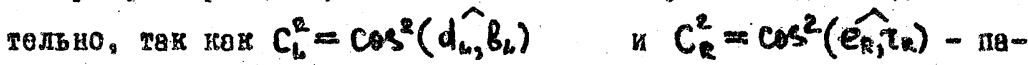
раметры опредедяют угш смешивания соответствуюших тастия; то

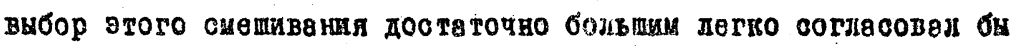
предсказвин модели о энспериментами [25]. Заметим; что экоперименты по еd-рассеянип [26]. пвреметризация тоторых zakxө меняетсп

$$
\begin{aligned}
& \tilde{a}_{1}=-\left[\left(1-s_{L / 3}^{2} / 3\right)-\frac{20}{9} \sin ^{2} \theta_{W}\right]\left(1-s_{R}^{2}\right) ; \\
& \tilde{a}_{2}=-\left[\left(s_{R}^{2}+1\right)-4 \sin ^{2} \theta_{W}\right] ;
\end{aligned}
$$

но противсречяг атоЙ возиохности, ввиду большо эи әкпериментөль-

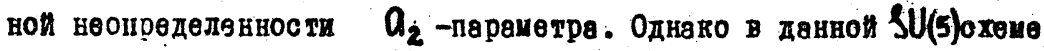
оба угле оказывартся хестко связанании

$$
\operatorname{tg}\left(\hat{e}_{R}, \tau_{R}\right)=\left(\frac{q_{1} \rho}{\sqrt{2}}\right) \frac{1}{m_{\tau}} ; \operatorname{tg}\left(\hat{\alpha}_{L}, \hat{B}_{L}\right)=\left(\frac{q_{1} \rho}{\sqrt{2}}\right) \frac{1}{m_{l}}
$$

и более того $C_{R}^{2}$-параметр не могет быть изменея, так определяет "экзотические" распады $\tau$-лептона. Поодедния поке 


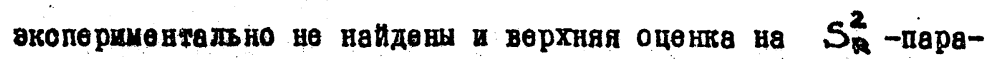
MeTp eOrs

$$
S_{R}^{2} \leqslant 40^{-4}
$$

पто, өстественно, нө даөт возмохности изменить предсгезания аффектов нарушения чө тности данноћ $S U(5)$ модеди по орввненар О модөльр [8]

8десь, однако, сраву виден выход из этон ситуации. Необходимо изиенить мультиплетную композишио спинорных поден гаким образои, чтобы параметрн $C_{L}^{2}$ и $C_{R}^{2}$ - сталп бы незавиомини. Оказивается, это легко сделать переопределив $\Psi_{L_{2}}-$ мудь типлеты, ваменотИ,

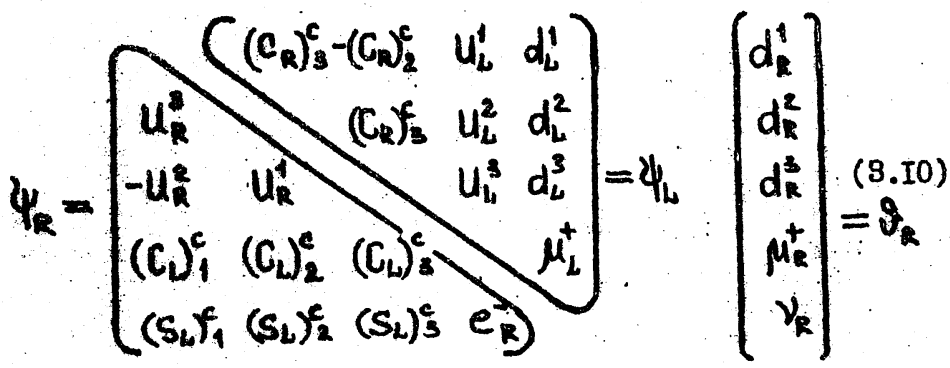

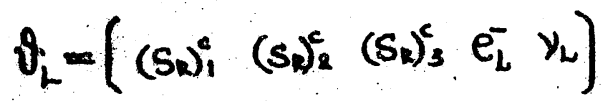

Перөопределение $U_{R}, C_{R}$-кварков делать не обязательно, тан . жак этот вопроо ћасвется в значительной степөни, дишь фөномөнодогии распада протона и долщен обсуддаться особо. Теперь $C_{L}^{2}$ п $C_{R}^{2}-$ вөличини фигсируются раздичньди параметраии $\operatorname{SU}(5)-$-төория

$$
\left.\operatorname{tg}\left(\hat{e_{R}, \tau_{R}}\right)=\frac{1 q, p}{(\sqrt{2}}\right) \frac{1}{m_{\tau}} ; \operatorname{tg}\left(\hat{d_{L}, t_{L}}\right) \approx\left(\frac{q_{2} \sigma}{\sqrt{2}}\right) \frac{1}{m_{t}}
$$




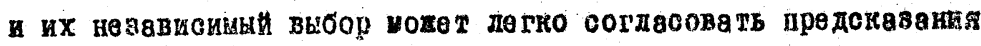
aтоп версия SU(s) төории с экоперинентани [25] и [26]. Пол-

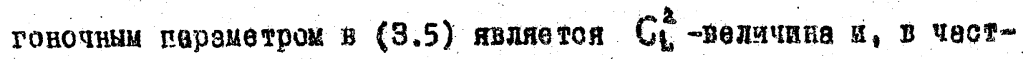
ности, рөзультате әкспериментов [25] и [26] оудут нө противорөчизы, өсли

$$
B_{i}^{2} \approx 0.1
$$

Таким ооразоу, для \&U(5) модеди [7] проблемы в обълонения

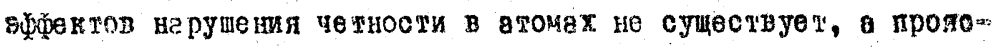

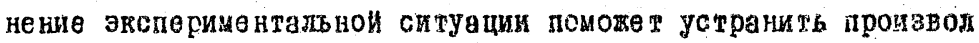
модэли в определенаи өө мущь типлеткои помпозичй.

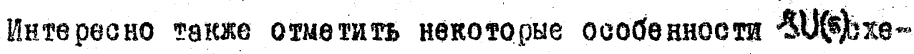

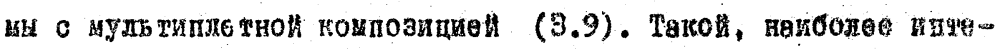

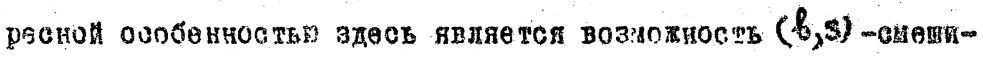

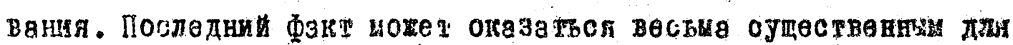

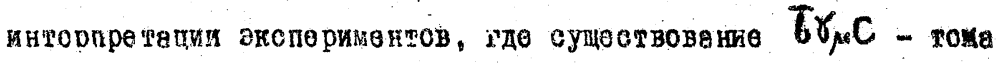

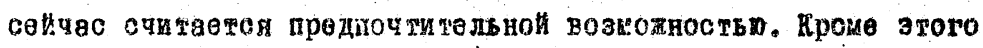

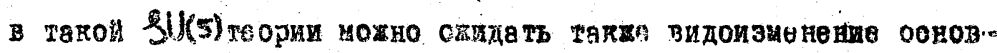

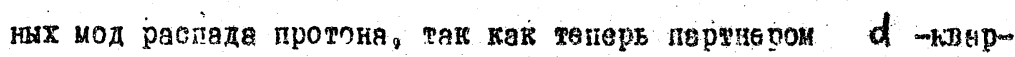

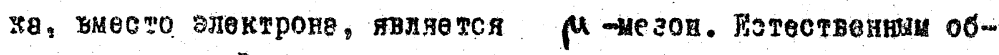

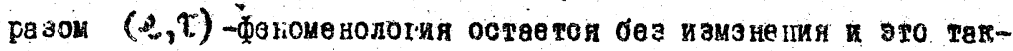

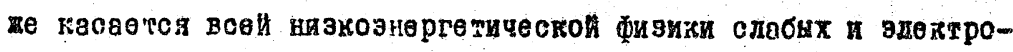
магнитвих взаимоденс чвиИ.

4. ОЧН РАHНЯЯ ВCEЛЕНHAЯ

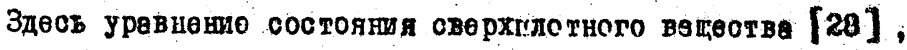
получянное в рамках $S U(5)$ теории применено к описанио терчодинамических свонств Вселөнноһ ва очөно раннои отајре өө эволюши при төипературах $10^{I 5} \leqslant \mathrm{~T} \leqslant$ I0 ${ }^{\mathrm{I}} \mathrm{GeV}$. Предполага- 
өтоя, что в өтоћ облвоги төиператур Вселөнная расшиядась рөвновеоно, исклочая, конөчно, гравитешионное ивлучение. 4 сохалени вдиного иневия по этому поводу нег $[29,30]$. Однако, нам капегоя, что аргументы, выдвинутые против равновесного рөоширения Всөдениои, на этой стадии өө әводюции, несоотоятельвн.

В этой өвязи, в согласии о работои $[30]$, здесь считвет-

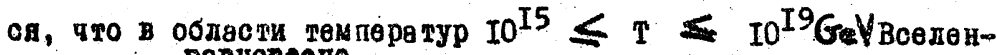

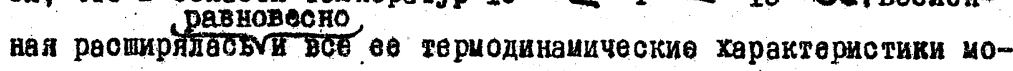
Гут бать получены в рамках равновеснон статистики. Пооледняя, в полном объеме, опредөляется териодинамическим потенциялом, дая которого нөми иопольауе тся выраженде, характерноө ддя всимптотически свободных төорић

$$
\Omega=-T\left(a+\frac{8}{\ln T / T_{0}}+\frac{c}{\ln 3 T^{3 / T_{0}}}+O\left(\frac{1}{\ln ^{2} T / T_{0}}\right)\right)
$$

дая $\boldsymbol{S U}(5)$-нодели ковффишиент. $a, b$, и $c$ приведены в работө [28] \#). Ниге в рамках (4.I) вайдено уревнение состояния вещества на рөннен стадии аводюции Всөленной и получөн ванон падевия төипературы при еө рвстирении. обсугдартся төкео некогорне следствия. В чвстности, дана оценке температуры грввите-. роонного издучения и нећдено влияние на өө величину конечноо Масосн нөйтрино.

Расует космологического расширения проведөя, следуя внрамөпио дия әфцективного давдения, получвечого нөпосредственно

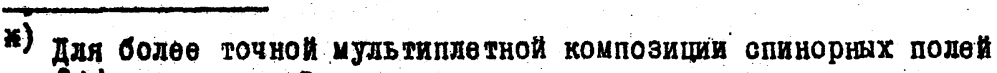
SU (5) модели [ $]$ аначения әтих коэфФициंентов имелг вид: $\theta=28.9$ - $B=-106$ , $c=580$ 
ив (4.I) көк $p=-\Omega / V$. Опрөдөляя двлөө плогность әнөртии кек фувкши төипературы

$$
\varepsilon=T^{2} \frac{\partial}{\partial T}\left(\frac{p}{T}\right)
$$

и искиючая әөгеи төипературу из (4.I) и (4.2) получвен нухнов вырахевия для урввнения состояния ведестве не реннећ ствдия 8 зольщй Вселенно

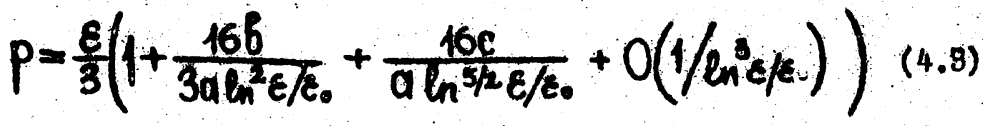

Это уравнение является основополагающи для дальнениих раочө208. Характерно логарифиические поправки в (4.8) явллогоя прямн сдедствиеи постудата асимптотическои свободы. Эавя уравнение состояния вещества можно рассчитатв парекөтры расmиряющенсея Вселеннои, рөшая уравнения Эинштеине

$$
\dot{R}^{2}=\frac{8 \pi G}{3 c^{2}} \varepsilon R ; \quad \frac{d \dot{ }}{d R} R=-3(\varepsilon+p)
$$

Иоклочвя из $(4.4)$ мастгабны фактор $R(t)$ и иопольауя $(4.8)$

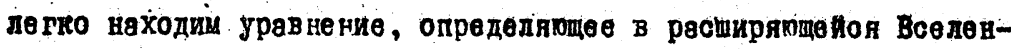
ноһ изиенение плотности әнерги в зависимости от төмпервтурв $\varepsilon^{-3 / 2} \varepsilon=-\left(1+\frac{4 b}{3 a \ln ^{2} \varepsilon / \varepsilon_{0}}+\frac{4 c}{a \ln ^{3 / 2} \varepsilon / \varepsilon_{0}}+\cdots\right) \frac{8}{c} \sqrt{\frac{2 \pi G}{3}}$

Решеви $(4.5)$ в области мадых $t$ имеет вид:

$\varepsilon(t)=\frac{3 c^{2} t^{-2}}{32 \pi G}\left(1+\frac{2 b}{3 a \ln ^{2} t / t_{0}}+\frac{\sqrt{2} c}{a \ln ^{5 / 2} t / t_{0}}+\cdots\right)$

Вависимость температуры Вселеннон от еө возраста находитол с помопьо $(4.2)$ и $(4.6)$. Здеов получаем: 
$T(t)=\left(\frac{c^{2}}{32 \pi G a}\right)^{1 / 4} t^{-4 / 2}\left(1+\frac{b}{2 a \ln t / t_{0}}+\frac{c}{a \sqrt{2} \ln 3 / 2 t / t_{0}}+\cdots\right)$

Вирахөнд $(4.6)$ и (4.7) являютсп астрофизическини предсказапняих всимптотически свободных төорий больпого объединения. Коэффичиевти $a, f$ и $c$ вввиоят, конечно, от выборе модези,

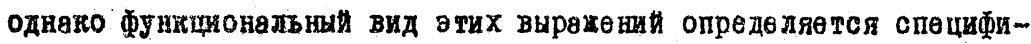
жон аскмдтотически свободного взаимодействия в' этих төориях.

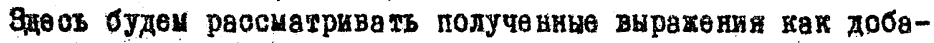
вочнй тенот проверки ворректности в работе [7]. В тастнооти, оденим темперетуру оуществующето сөнияо рөликтового грввитеционного ивлучения, которое вышдо 4. рөвновесия с веществом при пданковских төмпературах и охпахданось затеи в соонветствии с носмологически расширениен. Оотаваяоь в рөмках SU(5)-модөли обсуддөется танхе вопрос конечно ивосн нентрино в связи с определением ивсштабов хөрактернах времеп өводюци Вселөннон. Найдөна связь мехду возрастөм Веөленноћ и массон нентрино, которое в $3 U(5)$-иодели представлено однии 4-х номпонентнам дирековским спинором. При обсушденаи әтого рөзудьтата ми видим некоторое нөсоглясие поолөдних әкспернментель ных данных по определения массы нентрино [I5] и существуошећ оценкон вовраста Вселенноћ.

Характөрны часттаб эволюшии раннећ Вселенноћ отиечөн ве-

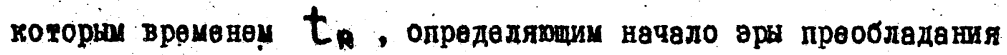
ведөотва. При $t \ll t_{R}$ эволютия воелөннои опрөдөляется прөдельныuห уравнения . состояния

$$
p=\frac{\varepsilon}{3} ; \quad T_{g}(t)=\left(\frac{c^{2}}{32 \pi G a}\right)^{1 / 4} t^{-1 / 2}
$$


которне эдесь являются асимптотиками вырахенин $(4.8)$ (4.7). В $\quad \mathrm{UU}(5)$ төории

$$
T_{g}(t)=4.5 \cdot 10^{9} \cdot t^{1 / 2} \text { (cer) } \quad t \ll t_{R} \text { (4.9) }
$$

После нөступления әрк прөобдадания вөцествя при $t \gg t_{R}$ изме-

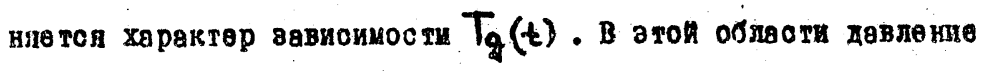
ствновится нөсуцественни $(p \ll \varepsilon)$ и урөвнония эннтенне (4.4) имевт сзоим решениеи другую всимптотику масттабного

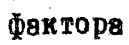

$$
R(t) \sim t^{2 / 3}
$$

Тенпературе гревитяционного излучения төперь изиеняет овоп вависиность от врөкени

$$
T_{g}(t)=\frac{4.5 \cdot 10^{9}}{t^{2 / 5}} t_{R}^{1 / 6}(\mathrm{ces}) ; t \gg t_{R} \text { (4.II) }
$$

причөц вдөсь ци считаеи, что в пропессе рөсширөми Всөлөннон

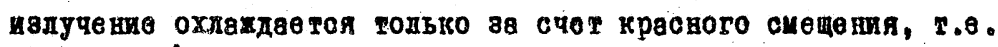
$T g \sim R^{-4}(t)$. Ннтерполяционные фориуль (4.9) ఇ (4.II)

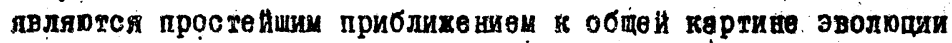
ранне Вседенноћ. Бодео точныһ јчет спепифик $S U(5)$ чодеди вдеоь пота не имеөт синсла.

Одехия, сдедуя (4.II), теипературу тревитешионного иаду-

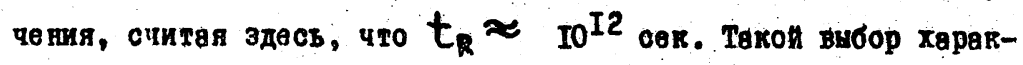
төрного иасштвба времеки определяется рөкошбннашей водорода не раннен стадии әводоции Вселеннок. При әтон очнтвеи такхе, что $t=1.8 \cdot 10^{\text {IO }}$ де г соотве тоныет возрасту Вселенноћ. Torдa

$$
T_{g} \approx 0.65^{\circ} \mathrm{K}
$$

Такая оценге төипературн гравитационного ивдучения хорощо со- 


$$
-35
$$

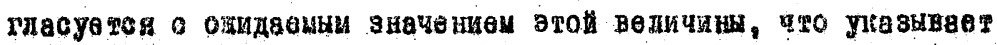

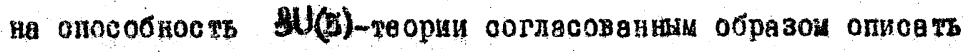
полиур картину вволюиим раннен Всененной.

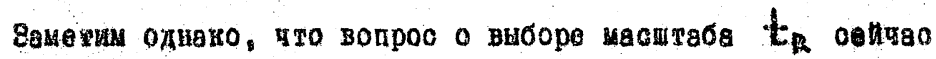

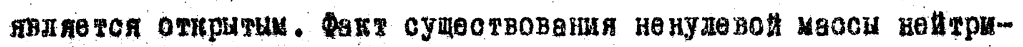

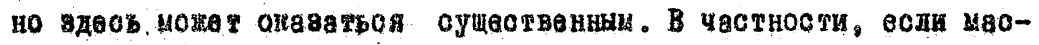
ая нентрино будет соотвато твавать предеказанид работн [15],

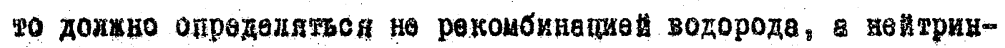

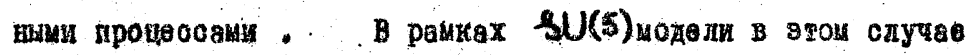
one unta

$$
t_{n}=3.7 \cdot 4\left(\frac{m_{e}}{m_{v}}\right)^{2} \text { (cen) }
$$

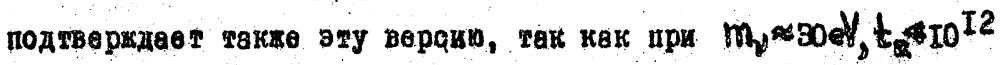

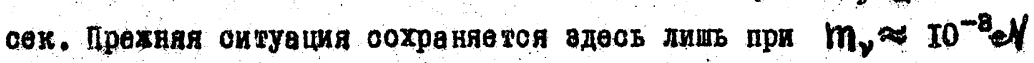

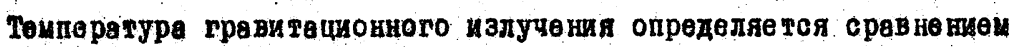

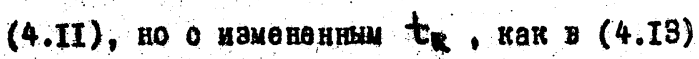

$$
T_{g}(t)=z_{1} p^{2}\left(\frac{m_{l}}{m_{v}}\right)^{1 / 3} t^{-2 / 3}
$$

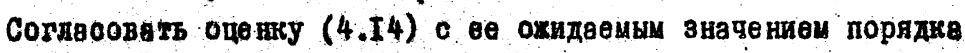

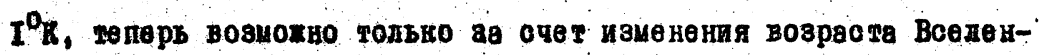

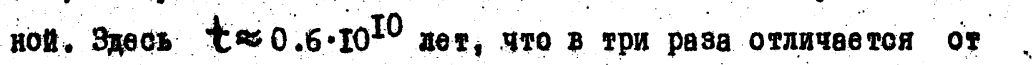
прехвих данных.

Ревомируя мохно утверхдвть, что асимптотически овободная $\mathcal{S}(5)$ төория өдиного взаимодеНостви, оказадась способнон равумным обрвзок объяонить ряд вахных астрофизических данншх,

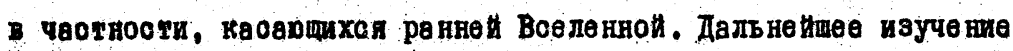

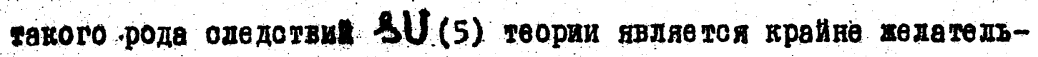
מаi, так как позволит продолаить ряд новых төотов для өө проBepru. 


\section{Conclue 1on.}

The present paper points out ope experimontel teate : cheoking the wellability of aejuptotionlly Proe 80(5)loxy euggeated earliex in the papers $[2,7]$ of the authox. 1 this veralon of the so(5)-theoxy is elaborated up to oparieon with expeximent and opene up a prowlalig direction devoloping the Grand Uniflcation theoxy (GOT). The anympHoally froe su(5) theory of Grand Onlfication as beling Intringicalis eelfconestatent (fxes of the "ropo-ohazge (f1oulty) construotion aekes a reliable soundation fox reloping experivental Invertigation of the high and aupengh onergy phyalos and makes it poselble to reach a deopor lexetanding of the Idean underlying 1t. The experimental odlotion of buoh a theoxy are fax wore xoliable than thoee the etandera theory and thic 10 eapocially Important now at the new experivente which ooncern tho fundawontal prinpleo of elewentary part1010 phyolon are boing planned.

Is an Imediate tact one rooggniseo the expexiwental voIlevtion of the proton inotability raion in Initiated by

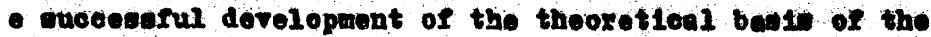

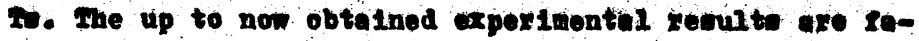

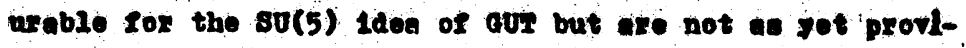
In - omplete information about ite valiats. It is, vertivelew, belorod that the ancwor to the quedtion will I obtained within the noxt for joare, although the upper

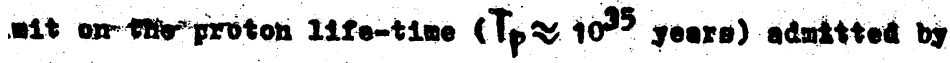


the $30(5)$ theory may well fall beyond the ramge of exportwonty peasiblittios. It 10, therafors, toglogl to otart thinking

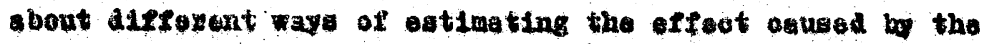

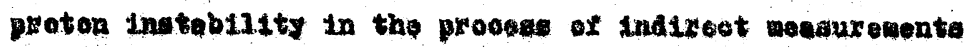
basing on a wore couplote use of the Interxolationa amang

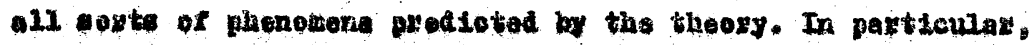

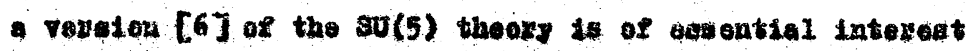
wherein the protion life-time to olowaly correlated with the value of the was of the $e, f$ mantrino. In this theory $m_{y} \leqslant$ $\leq 10^{-3}$ or and thit value of the wase, if confixwed, vilu provide a moxe sceurate ovaluation of the proton life time. By the way, the problew of einitepean of the nase of this neutrino is itgelf of latereat and worth of thorough expezion pental study. The up-to-dete expeximental entimato of this mase (which is about 30 or [15]) neede to be made more precies. The oomplete analyete of the noutrtne phonomenology apooup1ishod in thes paper way serve a good guide to aetion in thite respeot.

Tho onalyale of the oxportmontal attuation conoerning the wesreh for the parity violating offects in atome bas. domonetrated that tho su(5) nohem or our is oomplotely copplatont, tho luxurity of the Isnal oboto of the waltiplot compenition beting loft to the exporiment. If, howorex,

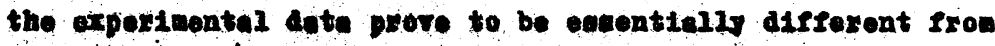
thowe predioted by the rotrberg-Balam nodol the otandar?

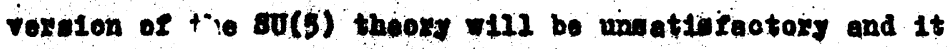
will be poseible to rehabilitate the 1dea of the $80(5)$ aUT 
oniy within the examerrosk of the godyited so(5) theory, in which the $(u, d)_{h}$ and $(c, s)_{h}$ quarte are interplaced. The sU(5) theory 00 modifled han a number of poovilar convequenoon whioh way alreads today becowe a eubjeot of experimental invest1gations. The dixeot vexifloation of this modifiod so(5) rexsion take wa back again to ase detaliod atudy of the phenomenology of the proton deovy, an rell ae other offoct mediated by the leptoquark bollons. TheBc axperimente atill belong to the future. Mere prowieing axe today Indizeot expeximente. For Instance, the experiwental progxamo almed at making the nase wpeotrue of light leptoni more pro-

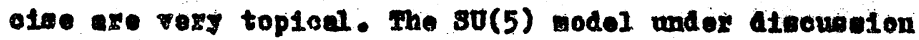
prodiot the existence of another oharged 8 -lepton (whioh extende the $e, \mu$-undioreality to the $\tau, j$-part10les) with the wase about 40 Ger. The enatoh for auch a lepton is an Indopendent and very Important experivental tanke Ite diboo-

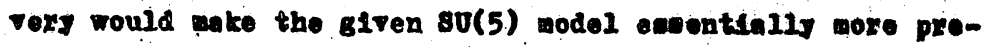
oles. Osing indizeot prediotion of thie moke precise nodel one night next obtain rather complete lupoxnatlon obout the itzuotux of the processes responeiblo for the parity violation effeots in atow and the proton decen.

It would be aleo of contidorable Interest to make the phonowenology of the $\tau$-leptor woze procteo and oepoolall to claxify the question about the wase of the $N_{\tau}$-noutrinoe Hoxe, an the wost pronieing diroction of experimontal etudy ono whould think of a seaxoh por exot10 decays of the 


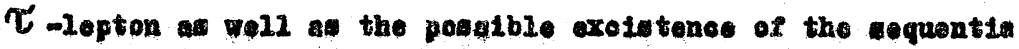
ceaje whioh world alyect2y indicate the exalatenae of the hoovy weutring espociated with the $\tau$ mlepton. whie hoav $N_{\tau}$

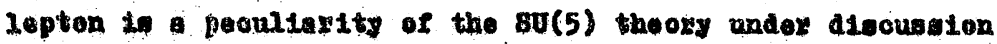
and does not es yot disagree with the exioting exporimentil ustuation.

It Is woxth aoting onoe again that, in the whole, ace sign ox contradiotion with the ex inting experimentel data

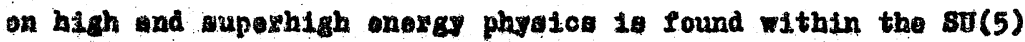
theogy under difcuselon. On the contraxy, its prediotions oompletely agreo with these data. It is important to realise. howevex, that thene ata axe atill not couplete exough to IIx In unique way all the parametera of thin 80(5) theory and Is thio oense there is somo noninglevaluednees in its predict1one. One noede to know at least two more experimentel facta of the oof disousaed above.

The author finde it pleasant to express hio deop grati-

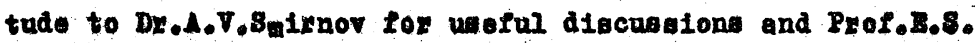
Fradkin for veluablo advices and the permanent interest in the work. 


\section{REFBREMCES}

1. H.Ceorg1, S.I.Glashow, Phre. Rev, Lott., 32 (1974) 430.

2. B.3. Hredkin, O.K.Kalemhnikor, Phye. Lotto, 648 (1976) 177.

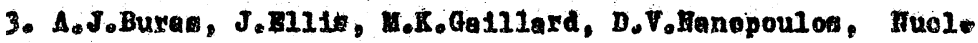
Thys.. 135B (1978) 66

4. H,-B.Obang, A.Dat, JePerez-Hexcader, Phys. Intt., 238 (1980)

5. I.D. Teandau, I.Y.Pomeranchuk, Dok1. Aced, Wauk US8R 102 (1955) 4.89.

B.S.PradkIn, 2h.tkep. Teox. F18., 2B (1955)750

6. Bos.PradkIn, 0.KoKalashnikov, Lett. Nuovo C1mo, 89 (1980) 455

7. 0.K.Kn Iaghnikov, Prepxint tobedev Phye. Ineto-80/166

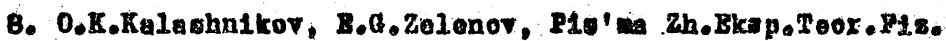
$23(1981) 560$

9. Tr.I.Az1mov, I.I. FrankPuxt, A.V.Khose, Ogp. T12. Mauk, 124 (1978) 459

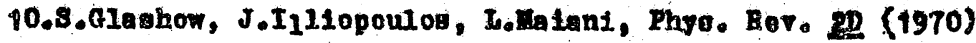
1285.

11.T.P.Cheng, B.E1ohten, Io-P.I1, Phya. Rev, 21 (1974) 2259.

12.0.K.XaIaahnikor, V.B.Vologodak, Pxeprint Iobeder Thyo. Inte $-81 / 108$

13.Ia.B.Zel'dov1toh, Dokl. Aogd, Hauk UBSA B6 (1952) 505 8.J.Konopinakt, M.llahwound, Phye, Rer. 22 (1953) 1045

14.H:Cloorg1, S.We1nberg, Phy. Bor., I7D (1978) 275 ,

P.Payet, Pxeprint CERA, 1980, TH.2907 


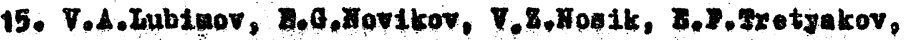
V.8.ILosk, Thys. Iott, 24 (1980) 266,

16. Yothe Reyl ot al, Phys. Iotte, 63B (1976) 466 .

17. Y.-8.7aa1, Phye, A970, 生 (1971) 2821.

E.Pujitawa, B.Kawaooto, Phys, Aev. 14 (1976) 59

10. J.P.Donoghue, I.Holtonatein, Phya, Revo, IID (1978) 224;

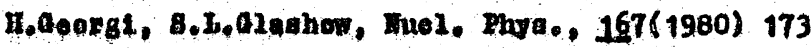

19. Y.Ahn, J.Kum, H.G.Bong, Phwe. Iatt., Z3B (1978) 196;

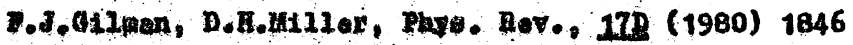

20. 8.U.B1lonky, B.Pontecorvo, Phys. Report 110 (1978) 225;

A.De Anjule, H.Tusignoli, I.Heiant, S.7.Potwov,

R.Potronsto, Truc1. Phys, 1689 (1980) 54

81. A.A.droelu, Huol. Bhye., 15461979) 485

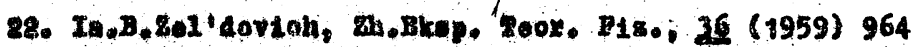

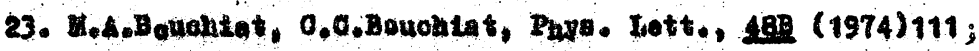

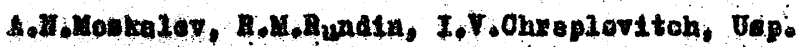

D1s. Vauk 119(1976) 409

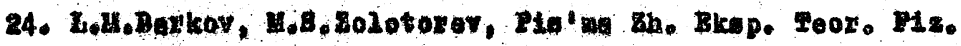

26 (1978) 379, Thye, Lott, o58 (1979) 309.

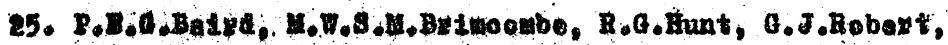

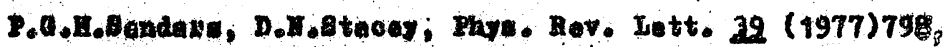

Hotolovie, J.H.Hollioter, D.0.80xeide, B.Q.IIndahl,

B.H.Poweton, Thys, Revo. Iott. 2 (1977),795;

Ju.t.Bogdanor, I.I.Bobelman, V.H.sorokin, I.I.8truk,

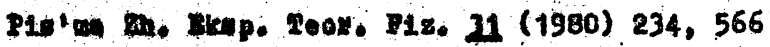

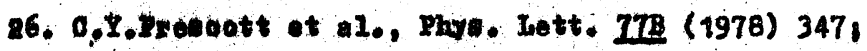

MA (1979) 524. 
27. P.Q.Fung, J.J.Sakwial, Phye. Inett. Beg (1979) 91

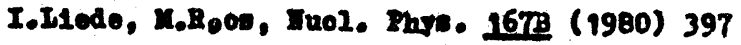

28. O.X.Xelachnikev, T.V.X11nov, Zreprint Lobedov Prye. Inot. - 60/105

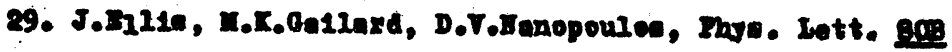
(1979) 360

30. D. Wesmbere, Inva. Rev. Intt. $42(1979) 650$ 


$$
\text { T - } 2144
$$

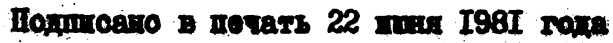

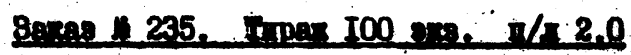

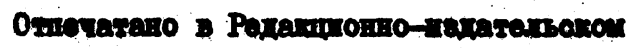
opraxe OAH CCCP Mooxsa, B-3I2, Iomiromall upoonors, 53 